\title{
miR-133: A Suppressor of Cardiac Remodeling?
}

\section{OPEN ACCESS}

Edited by:

Paulo Correia-de-Sá,

Universidade do Porto, Portugal

Reviewed by:

Andrew F. James,

University of Bristol, United Kingdom

Paola Rizzo,

University of Ferrara, Italy

*Correspondence: Qizhu Tang

qztang@whu.edu.cn

†These authors have contributed equally to this work

Specialty section:

This article was submitted to Cardiovascular and Smooth Muscle

Pharmacology,

a section of the journal

Frontiers in Pharmacology

Received: 07 March 2018

Accepted: 23 July 2018

Published: 17 August 2018

Citation:

Li N, Zhou H and Tang Q (2018) miR-133: A Suppressor of Cardiac

Remodeling?

Front. Pharmacol. 9:903.

doi: 10.3389/fphar.2018.00903

\author{
Ning $\mathrm{Li}^{1,2,3+}$, Heng Zhou ${ }^{1,2,3+}$ and Qizhu Tang ${ }^{1,2,3 *}$ \\ ${ }^{1}$ Department of Cardiology, Renmin Hospital of Wuhan University, Wuhan, China, ${ }^{2}$ Cardiovascular Research Institute, Wuhan \\ University, Wuhan, China, ${ }^{3}$ Hubei Key Laboratory of Cardiology, Wuhan, China
}

Cardiac remodeling, which is characterized by mechanical and electrical remodeling, is a significant pathophysiological process involved in almost all forms of heart diseases. MicroRNAs (miRNAs) are a group of non-coding RNAs of 20-25 nucleotides in length that primarily regulate gene expression by promoting mRNA degradation or post-transcriptional repression in a sequence-specific manner. Three miR-133 genes have been identified in the human genome, miR-133a-1, miR-133a-2, and miR-133b, which are located on chromosomes 18, 20, and 6, respectively. These miRNAs are mainly expressed in muscle tissues and appear to repress the expression of non-muscle genes. Based on accumulating evidence, miR-133 participates in the proliferation, differentiation, survival, hypertrophic growth, and electrical conduction of cardiac cells, which are essential for cardiac fibrosis, cardiac hypertrophy, and arrhythmia. Nevertheless, the roles of miR-133 in cardiac remodeling are ambiguous, and the mechanisms are also sophisticated, involving many target genes and signaling pathways, such as RhoA, MAPK, TGFB/Smad, and PI3K/Akt. Therefore, in this review, we summarize the critical roles of miR-133 and its potential mechanisms in cardiac remodeling.

Keywords: miR-133, fibrosis, hypertrophy, electrical remodeling, reprogram

\section{INTRODUCTION}

Heart failure (HF), a rapidly growing public health issue, had an estimated prevalence of over 37.7 million individuals worldwide in 2016, contributing to a grave disease burden (Ziaeian and Fonarow, 2016). As a ubiquitous clinical manifestation of various end-stage heart diseases, HF is distinguished by interstitial fibrosis, chamber remodeling, reduced ventricular compliance, and abnormal electrical conduction (Chamberlain et al., 2015; Lee et al., 2015). Cardiac remodeling is one of the decisive pathophysiological processes, exhibiting multiple roles in HF (Saba et al., 2008). Cardiac fibrosis, hypertrophy, and electrical remodeling are the most important physiological or pathological changes observed in cardiac remodeling and directly affect the cardiac function and even cause death (Tao et al., 2016). Therefore, investigations of the associations between cardiac remodeling and risk factors, as well as the molecular mechanisms are important and will contribute to the development of novel and effective approaches to protect against HF.

MicroRNAs (miRNAs) are a class of small non-coding RNAs of approximately 20-25 nucleotides in length that are typically excised from putative miRNA precursor (pre-miRNA) with 60-110 nucleotides and play vital biological roles by directly binding to the $3^{\prime}$ UTR of target messenger RNAs (mRNAs) (Pan et al., 2017). By pairing with target mRNAs encoding proteins, miRNAs could regulate the expression of these mRNAs at the post-transcriptional levels (Calin and Croce, 2006), in addition to affecting the stability and/or the translation of mRNA (Xiao, 2011). Many miRNAs 
participate in various crucial biological processes in the human body, including proliferation, differentiation, development, and cell apoptosis (Vidigal and Ventura, 2015). Based on accumulating evidence, miRNAs function as important regulators of cardiovascular disorders, such as hypertension (Courboulin et al., 2011), stroke (Jeon et al., 2013), atrial fibrillation (AF) (Goren et al., 2014), left ventricular hypertrophy and HF (Wronska et al., 2015). Using cardiac fibrosis as an example, miR-22 may inhibit angiotensin II (Ang II)induced cardiac fibrosis and the transformation of cardiac fibroblasts to myofibroblasts by suppressing the expression of transforming growth factor $\beta$ (TGF- $\beta$ ) receptor I (T $\beta$ RI) in the heart (Hong et al., 2016). Moreover, miR-101a also inhibits the expression of T $\beta$ RI and its downstream molecules to suppress differentiation, migration and collagen synthesis of cardiac fibroblasts (Zhao et al., 2015). However, miRNAs also act as accomplices in cardiovascular disorders associated with cardiac fibrosis. The miR-34 cluster, particularly miR-34a, is up-regulated in the heart following myocardial infarction (MI). By directly targeting Smad4, miR-34a exacerbates the progression of cardiac fibrosis, suggesting that inhibition of miR-34a may be a promising strategy to treat cardiac fibrosis (Huang et al., 2014). Additionally, miR-21 has been also shown to promote the transduction of extracellular signal-regulated kinase/extracellular signal-regulated kinases-mitogen-activated protein kinase (ERK-MAPK) signals, thus aggravating cardiac fibrosis and deteriorating cardiac function (Thum et al., 2008). Hence, different miRNAs may exert diverse effects on cardiac remodeling, but the underlying mechanisms remain unclear.

In the present review, we synthesize the roles and mechanisms by which miR-133 protects against cardiac remodeling to provide logical evidence for further investigations and clinical applications in the future.

\section{CARDIAC REMODELING}

Cardiac remodeling is generally accepted as constant adjustments of the myocardium to the structure, metabolism and electrical conduction under the influence of various endogenous and exogenous factors, which eventually result in alterations in the ventricle structure and biological effects (Cohn et al.,

Abbreviations: HF, Heart failure; miRNAs, MicroRNAs; Ang II, Angiotensin II; MI, Myocardial infarction; ECM, Extracellular matrix; $\alpha$-SMA, $\alpha$-smooth muscle actin; EMT, Epithelial-mesenchymal transition; MET, Mesenchymal-to-epithelial transition; AF, Atrial fibrillation; $\beta$-AR, $\beta$-adrenergic receptor transduction; CTGF, Connective tissue growth factor; SRF, Serum response factor; Col1A1, Collagen 1A1; TAC, Transverse aortic constricted; $\mathrm{IP}_{3} \mathrm{RII}$, Inositol 1,4,5-triphosphate receptor II; IICR, $\mathrm{IP}_{3}$-induced calcium release; NFAT, Nuclear factor of activated T cells; IGF-1, Insulin-like growth factor-1; ERG, Ether-a-go-go related gene; $\mathrm{As}_{2} \mathrm{O}_{3}$, Arsenic trioxide; MET, Mesenchymal-to-epithelial transition; iPSCs, Induced pluripotent stem cells; $3^{\prime}$-UTR, $3^{\prime}$-untranslated region; TGF- $\beta$, Transforming growth factor- $\beta$; MSCs, Mesenchymal stem cells; iCMs, Cardiomyocyte-like cells; CPCs, Cardiac progenitor cells; HSP, Heat shock protein; UTR, Untranslated regions; Mef2, Myocyte enhancer factor-2; MyoD, Myogenic differentiation1; APD, Action potential duration; Mps1, Monopolar spindle 1; cAMP, 3', $5^{\prime}$ cyclic adenosine monophosphate; MAPK, mitogen-activated protein kinase; ERK, Extracellular signal-regulated kinases; NFAT, nuclear factor of activated T cell; TGF- $\beta$, transforming growth factor $\beta$; HCNs, Hyperpolarization-activated nonspecific cation channels.
2000; Zhou et al., 2013). Generally, cardiac remodeling is classified as mechanical remodeling and electrical remodeling, according to the mechanisms by which this process contributes to cardiac dysfunction (Jeyaraj et al., 2007; Lellouche et al., 2011). Depending on the type of cardiac cells exhibiting pathological changes, mechanical remodeling is further classified as cardiac fibrosis and cardiac hypertrophy (Gerdes and Capasso, 1995; Kamireddy et al., 2009).

\section{Mechanical Remodeling}

In cardiac fibrosis, the excessive deposition of extracellular matrix (ECM) proteins secreted by cardiac fibroblasts reduces tissue compliance and accelerates the progression of HF (Travers et al., 2016). Various quantitative and qualitative changes in the interstitial collagen network, which usually occur to enable the cardiac tissue to adapt to ischaemic insults, drugs, systemic diseases, or any other harmful stimulus that affects the heart itself and the circulatory system, can trigger cardiac fibrosis (Travers et al., 2016). The harmful stimulus induces cardiac fibroblasts to transiently express $\alpha$-smooth muscle actin $(\alpha-$ SMA), an actin isoform that is a marker for myfibroblast and mainly responsible for the homeostasis of the ECM (Hinz et al., 2001). The $\alpha$-SMA protein in cardiac fibroblasts is connected to the ECM through focal adhesions, and is assembled into stress fibers and remodels the surrounding ECM in response to certain types of stress, eventually causing HF (Leask, 2015; Tian et al., 2017). Although several studies have explored the origin of cardiac fibroblasts, accurate answers are still unavailable. Nevertheless, cardiac fibroblasts are generated from multiple sources, such as the proliferation of existing fibroblasts, the recruitment of pericyte-like progenitor cells, differentiation of resident mesenchymal cells mediated by growth factors or even the epithelial-mesenchymal transition (EMT) (Hinz et al., 2012). In recent years, the cellular microenvironment was also disclosed to play a vital role in enhancing the pathological responses of cardiac fibroblasts to growth factors/cytokines and hormones during cardiac fibrosis (Gao et al., 2016).

Cardiac hypertrophy is broadly defined as an increase in the myocardial mass to continuously pump blood to provide the organism with nutrients and oxygen (Sayed et al., 2007). It is one of the critical ways in which cardiomyocytes respond to physiological or pathological haemodynamic overload and neurohormonal stimuli, such as chronic exercise training, regular physical activity and gestation (physiological) or valve disease, hypertension, HF, and MI (pathological) (Lyon et al., 2015; Shimizu and Minamino, 2016). Both physiological and pathological cardiac hypertrophy may lead to an increase in cardiomyocyte size to improve their functional output and maintain cardiac function, without altering the number of cardiomyocytes (Tham et al., 2015). Notably, physiological hypertrophy is reversible and is characterized by normal cardiac morphology (no apoptosis and fibrosis) and normal or enhanced cardiac function (Kamo et al., 2015). Conversely, pathological hypertrophy, which exhibits the hallmarks of increased protein synthesis and alterations in the organization of sarcomere structure in cardiomyocytes, is generally followed by deleterious events involving cardiac dysfunction, cardiac fibrosis, oxidative 
stress, endoplasmic reticulum stress and fetal gene upregulation, including genes that encode brain natriuretic peptide (BNP), atrial natriuretic peptide (ANP), and $\beta$-myosin heavy chain ( $\beta$ MHC) (Bernardo et al., 2010; Huang et al., 2013; Gao and Wang, 2016). Initially, cardiac hypertrophy is an adaptive response to maintain cardiac output. However, abnormal growth may gradually spread to one chamber of the heart, one side of the heart, and even the entire structure of heart uniformly because of pressure or volume overload and other hormonal or cytokine stimuli, which may eventually lead to HF or sudden death (Morgan and Baker, 1991; Heineke and Molkentin, 2006).

To date, several studies examining the interplay between cardiac fibrosis and cardiac hypertrophy have focused on cytokines secreted by cardiac fibroblasts and cardiomyocytes. Figure 1 shows the cellular interactions in the heart. In fact, many of these cytokines could be modulated by miRNAs, and are expected to be their potential targets.

\section{Electrical Remodeling}

Electrical remodeling refers to alterations in the electrophysiological milieu of the myocardium in patients with various cardiac disorders, such as HF, ventricular hypertrophy, myocardial ischaemia, and infarction, which are commonly associated with cardiac arrhythmias (Mueller et al., 2011; Aguilar et al., 2014). Electrical remodeling is distributed into four classes, depending on the level at which remodeling occurs, including ionic channel remodeling, cardiomyocyte electrical remodeling, myocardial electrical remodeling, and cardiac conduction system electrical remodeling (Mitchell et al., 1993; Lee et al., 2017). Generally, the initial rapid phase and the terminal phase of ventricular repolarization in cardiomyocytes are triggered by a transient outward $\mathrm{K}^{+}$current $\left(\mathrm{I}_{\text {to }}\right)$ and inward rectifier $\mathrm{K}^{+}$ current $\left(I_{K 1}\right)$, respectively (Chen et al., 2017). In patients with $\mathrm{HF}$ and experimental HF models, the current densities of $\mathrm{I}_{\mathrm{K} 1}$ and $\mathrm{I}_{\text {to }}$ are significantly reduced, indicating that the reduction of $\mathrm{I}_{\mathrm{K} 1}$ and $\mathrm{I}_{\text {to }}$ plays a vital role in abnormal ventricular membrane repolarization (Zicha et al., 2004). These alterations might cause adverse ionic remodeling and result in an excess prolongation of the action potential duration, which eventually contribute to malignant arrhythmias (Huo et al., 2014). In essence, either functional impairments or alterations in the expression of channel proteins responsible for these ion currents may result in pathological decreases in these current densities in the heart (Marczenke et al., 2017). Hence, strategies that inhibit the downregulation of these ion channels are very important for preventing HF.

Taken together, cardiac remodeling is a sophisticated pathophysiological process in HF and involves many types of cells, molecules, and signaling pathways, which represent numerous potential miRNA targets, thus miRNAs may modulate any of the links in the cardiac remodeling process to ameliorate or aggravate disease conditions.

\section{THE BIOGENESIS, STRUCTURE AND TARGETS OF MiR-133}

MiR-133 was first experimentally characterized in mice and its homologs were identified in several other species, including invertebrates such as the fruit fly Drosophila melanogaster (Chen et al., 2006). In the human genome, miR-133 genes include miR133a-1, miR-133a-2, and miR-133b located on chromosomes 18, 20 , and 6, respectively. Importantly, miR-133a-1 and miR-133a2 have identical nucleotide sequences, whereas miR-133b differs in the last 2 nucleotides $(\mathrm{GU} \rightarrow \mathrm{A})$ at the $3^{\prime}$ terminus. The three miRNAs are transcribed as a bicistronic transcript with miR1-2, miR-1-1, or miR-206, respectively, as shown in (Figure 2; Ohanian et al., 2013). Ten variants of miR-1 and miR-133 were

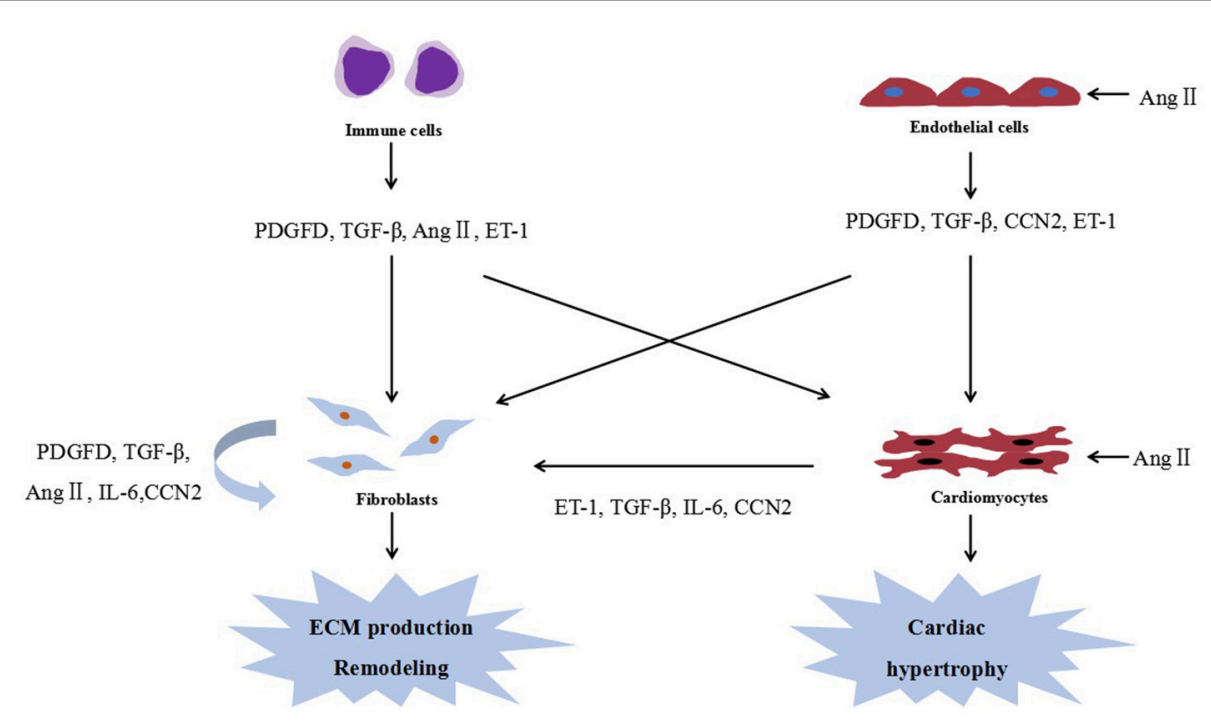

FIGURE 1 | Cellular interactions in the heart. Ang II, angiotensin II; PDGFD, platelet-derived growth factor D; ECM, extracellular matrix; ET-1, endothelin-1; IL-6, interleukin 6; and TGF- $\beta$, transforming growth factor- $\beta$. 


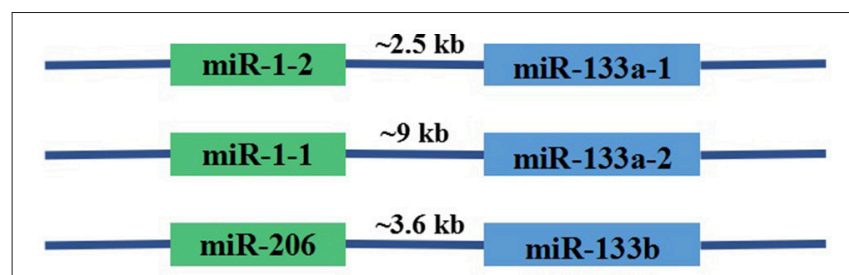

miR-133a-1: UUGGUCCCCUUCAACCAGCUGU

miR-133a-2: UUGGUCCCCUUCAACCAGCUGU

mir-133b: UUGGUCCCCUUCAACCAGCUA

FIGURE 2 | Basic information about the genomic organization of the miR133 family in mice. As shown in the figure, miR-133a-1, miR-133a-2, and $\mathrm{miR}-133 \mathrm{~b}$ are transcribed as bicistronic transcripts with miR-1-2, miR-1-1, or miR-206. Genomic distances between the miRNA coding regions are 2.5, 9 , and $3.6 \mathrm{~kb}$, respectively.

identified in 120 individuals with familial atrial fibrillation (AF). The miR-133a-2 haplotype comprises six nucleotide changes, namely, $-19 \mathrm{G}>\mathrm{A} ;-102 \mathrm{G}>\mathrm{A} ;-82 \mathrm{G}>\mathrm{A} ; 79 \mathrm{~T}>\mathrm{C} ;+69 \mathrm{G}$ $>\mathrm{A}$; and $+47 \mathrm{~T}>\mathrm{C}$. The miR133B haplotype only contains one variation, -25 delA. The miR-1 haplotype comprises three nucleotide changes, $-43 \mathrm{C}>\mathrm{T},+15 \mathrm{~A}>\mathrm{G}$, and $+74 \mathrm{~T}>$ C (Ohanian et al., 2013). The sites in which miR-133a and miR-133b are expressed also differ; the bicistronic miR-1/miR133a cluster is expressed in both skeletal and cardiac muscle, while the miR-206/miR-133b cluster is mainly expressed in skeletal tissue (Ivey et al., 2008; Liu et al., 2008). Many crucial myocyte differentiation factors, such as myocyte enhancer factor2 (Mef2), serum response factor (SRF), myogenic differentiation1 (MyoD), and myocardin, regulate the transcription of miR-1 and miR-133a (Zhao et al., 2005).

The miR-133 genes appear to be dysregulated in many human diseases, including gastric cancer (Yang et al., 2017), nonsmall cell lung cancer (Wang Y. et al., 2016), pituitary tumors (Wang D. S. et al., 2016), and various cardiovascular diseases (Liu et al., 2017). Insulin has been shown to regulate miR-133 expression. The insulin treatment triggers the translocation of active SREBP-1c from the endoplasmic reticulum to the nucleus, which concomitantly induces SREPB-1c expression via the PI3K signaling pathway. Consequently, the elevated level of active SREPB-1c suppresses the expression of MEF2C, a protein that binds to the enhancer region of miR-133. Due to the lower MEF2C expression, the transcription of miR-133a is reduced, eventually leading to decreased levels of its mature forms in heart and muscle (Granjon et al., 2009). Additionally, the gene polymorphism of miR-133 is also implicated with the metabolism of drugs. Pérez-Andreu et al. (2012) identified the potential binding sites for miR-133 in human hepatocytes and found that it was involved in regulating VKORC1 expression, a target of warfarin, in response to anti-coagulant treatment. Regarding the warfarin dose, patients carrying the rs $45547937 \mathrm{~A}$ allele of the miR-133a-2 gene required a significantly higher warfarin dose to achieve the therapeutic benefit than patients carrying the rs9923231 wild-type allele (Ciccacci et al., 2015).
As reported, miR-133 is predominantly expressed in cardiomyocytes and cardiac fibroblasts in the heart, and the overexpression, targeted deletion, or antisense-specific knockdown of miR-133 genes have revealed many of its functions and targets in cardiac remodeling (Townley-Tilson et al., 2010). For instance, in the study by Sang et al. a miR-133a mimic and miR-133a overexpression significantly decreased fibrosis in the heart by inhibiting serine/threonine kinase Akt in rats with chronic HF (Sang et al., 2015). During cardiac reprogram, miR-133 overexpression also suppresses the expression of a large number of genes in fibroblasts and concomitantly activates cardiac gene programme (Muraoka et al., 2014). Additionally, the downregulation of miR-133a expression results in the ectopic expression of smooth muscle genes in myocardium and aberrant cardiomyocyte proliferation by activating SRF, a positive cardiomyocyte-specific growth and differentiation factor that binds to the CArG boxes in the regulatory region (Liu et al., 2008). More recently, miR-133 was proven to modulate multiple components of the $\beta$-adrenergic receptor ( $\beta$-AR) signal transduction cascade to protect against cardiac fibrosis (Wang D. et al., 2017). Table 1 summarizes the abnormal expression of miR-133 genes and their targets observed in cardiac remodeling.

\section{THE ROLES OF miR-133 IN CARDIAC REMODELING}

MicroRNAs are atypically expressed in the cardiovascular system under some specific pathological conditions; the expression levels of miRNAs are usually altered when the myocardium is subjected to cardiac stress/insult (Da Costa Martins and De Windt, 2012). Although miR-133 is mainly expressed in the myocardium, and other copies of miR-133 have not been identified within the genome, miR-133 is dispensable for the heart development and cardiac morphogenesis because cardiac-specific or global deletion of miR-133 did not give rise to premature death or cardiac abnormalities in mice, and miR-133 null mice display normal fertility and viability. By contrast, miR-133 is essential for cardiac remodeling in response to different stresses (Matkovich et al., 2010). In a clinical study, the decreased expression of miR-133 was significantly associated with the severity of patients with HF. Patients with a high NT-proBNP concentration $(>1,800$ $\mathrm{pg} / \mathrm{ml}$ ) showed a $25 \%$ decrease in miR-133 expression compared with patients with a low concentration $(<300 \mathrm{pg} / \mathrm{ml})(p=$ 0.023) (Danowski et al., 2013). In animal models, miR-133 also exerts multiple functions to regulate the development of cardiac fibrosis, cardiac hypertrophy, electrical activities and cardiac reprogram. Figure 3 shows an overview of the roles of miR-133 in cardiac remodeling as well as some endogenous and exogenous molecules that are verified to regulate miR-133 expression.

\section{Inhibiting the Progression of Cardiac Fibrosis}

Cardiac fibrosis is distinguished by the excess deposition of ECM and the transformation of cardiac fibroblasts to myofibroblats; the deposition and the transformation negatively impact organ architecture and function ( $\mathrm{Wu}$ et al., 2017b). 
TABLE 1 | miR-133 and verified target genes involved in cardiac remodeling.

\begin{tabular}{|c|c|c|c|c|}
\hline Tissue/cells & miR-133 level & Target gene & Model & References \\
\hline Cardiomyocytes & Down & $\begin{array}{l}\text { RhoA, Cdc42, } \\
\text { Nelf-AWHSC2 }\end{array}$ & Mice and humans with cardiac hypertrophy & Carè et al., 2007 \\
\hline Cardiomyocytes & Down & Cyclin D2 & miR-133a double-mutant mouse & Liu et al., 2008 \\
\hline Cardiomyocytes & Down & Caspase-3 & Infarcted rats & Xu et al., 2014 \\
\hline Vascular smooth muscle cells & Down & $\mathrm{Sp}-1$ & Rats with balloon injury of the right carotid artery & Torella et al., 2011 \\
\hline Cardiomyocytes and fibroblasts & Down & Ctgf & Rats with hypertension-induced heart failure & $\begin{array}{l}\text { Duisters et al., 2009; } \\
\text { Angelini et al., 2015; } \\
\text { Li et al., } 2016\end{array}$ \\
\hline Cardiomyocytes & Down & IGF-1 & Mouse model of cardiac hypertrophy & Hua et al., 2012 \\
\hline HEK293 cells & Down & $\mid P_{3} R \|$ & Mouse model of cardiac hypertrophy & Drawnel et al., 2012 \\
\hline HEK293 cells & Down & Calcineurin & Rat model of pressure-overload cardiac hypertrophy & Dong et al., 2010 \\
\hline Atrial fibroblasts and atrial tissues & Down & TGF- $\beta$ & Canine model of atrial fibrosis & Shan et al., 2009 \\
\hline Embryonic fibroblasts & Up & Snai1 & Mouse & Muraoka et al., 2014 \\
\hline Cardiac fibroblasts & Down & Collagen 1a1 & Rats with cardiac fibrosis induced by angiotensin II & Castoldi et al., 2012 \\
\hline Cardiac fibroblasts & down & FGF1 & Mice with diabetic cardiomyopathy & Chen et al., 2014 \\
\hline Mesenchymal stem cells & Transfected & Apaf-1 & Infarcted rats & Dakhlallah et al., 2015 \\
\hline Cardiomyocytes & Up & $\mathrm{KCNH} 2$ & Guinea pig model of $\mathrm{As}_{2} \mathrm{O}_{3}$-induced QT prolongation & Shan et al., 2013 \\
\hline Ventricular myocytes & Down & Kcnip2 & Adult mouse hearts subjected to pressure overload & Matkovich et al., 2010 \\
\hline Heart/HEK293 cells & Up & HERG & Rabbit model of diabetic cardiomyopathy & Xiao et al., 2011 \\
\hline Cardiac progenitor cells & Up & Bmf and Bim & Mouse & Li R. et al., 2010 \\
\hline Zebrafish heart/cardiomyocytes & Down & $\mathrm{C} \times 43$ & Zebrafish model with partial heart resection & Yin et al., 2012 \\
\hline Rat ventricular cardiomyocytes & Down & NFATc4 & Rats with pressure overload-induced cardiac hypertrophy & Li Q. et al., 2010 \\
\hline C2C12 myoblasts & Transfected & $\begin{array}{l}\text { FGFR1 and } \\
\text { PP2AC }\end{array}$ & C2C12 cell lines & Feng et al., 2013 \\
\hline
\end{tabular}

A network of cytokines could regulate cardiac fibrosis, and abnormal activation of cardiac fibrosis is linked to various cardiac disorders through numerous molecular pathways and proteins. In particular, the transforming growth factor (TGF)- $\beta / \mathrm{Smad}$ pathway, mitogen-activated protein kinase (MAPK) pathway and PI3K/Akt pathway are several canonical signaling pathways participating in cardiac fibrosis.

\section{TGF- $\beta /$ Smad Pathway}

The TGF- $\beta /$ Smad pathway has been implicated in many fibrotic disorders, including liver cirrhosis (Kim et al., 2011), glomerulonephritis (Fukasawa et al., 2004), lung fibrosis (Yu et al., 2008), and vascular restenosis (Akiyama-Uchida et al., 2002). The TGF- $\beta /$ Smad pathway can regulate the endothelialmesenchymal transition (EndMT), meanwhile it is activated by the sarcomere protein mutation ( $\alpha$-myosin heavy chain, $\alpha$-MHC R719W) (Dijke and Hill, 2004). Under pathological conditions, the EndMT displays a critical role in the production of collagen and is predominantly regulated by signaling pathways mediated by cytokines, including TGF- $\beta$ (Yoshimatsu and Watabe, 2011). Connective tissue growth factor (CTGF), a cysteine-rich protein whose expression is induced by TGF$\beta$ through a signaling cascade requiring $\mathrm{Smad}$ and protein kinase $\mathrm{C}$ (PKC) in connective tissue cells, acts as a key regulator of cardiac fibrosis, which could give rise to collagen synthesis (Guo et al., 2015; Huang M. et al., 2016). On the other hand, the expression of mutant sarcomere proteins in myocyte cells also changes gene transcription in non-myocyte cells and contributes to the expression of profibrotic molecules, eventually inducing pathological remodeling in hypertrophic cardiomyopathy (Gong et al., 2011). In pathological remodeling, the activation of the TGF- $\beta /$ Smad pathway in non-myocyte is a pivotal mechanism underlying the increased fibrosis in patients with hypertrophic cardiomyopathy and a potentially important factor causing diastolic dysfunction and HF (Teekakirikul et al., 2010). Additionally, TGF- $\beta 1$ directly blocks PPAR $\gamma$ expression in cardiac fibroblasts at the transcriptional level, indicating that the down-regulation of endogenous proliferator-activated receptor $\gamma$ $(\mathrm{PPAR} \gamma)$ expression by TGF- $\beta$ is a key regulatory mechanism in cardiac fibrosis (Gong et al., 2011). Based on the findings from aforementioned experimental studies, we can conclude that the TGF- $\beta /$ Smad signaling pathway possesses a vital role in the cardiac remodeling process, particularly in cardiac fibrosis. In a study by Chen and colleagues examining a mouse model of diabetic cardiomyopathy, miR-133a significantly decreased the expression of TGF- $\beta 1$ and increased the expression of acidic fibroblast growth factor1 (FGF1) that could induce ERK1/2 phosphorylation (Chen et al., 2014). In atrial fibroblasts, however, cigarette smoking/nicotine exposure activated the $\alpha 7$ nicotinic acetylcholine receptor $(\alpha 7-\mathrm{nAChR})$ and decreased the expression of miR-133, thus increasing the expression of TGF- $\beta 1$ and resulting in enhanced collagen production as well as fibrosis generation (Shan et al., 2009). Apart from targeting TGF- $\beta 1$, in fact, miR-133a could also bind to the $3^{\prime}$ UTR of the CTGF 


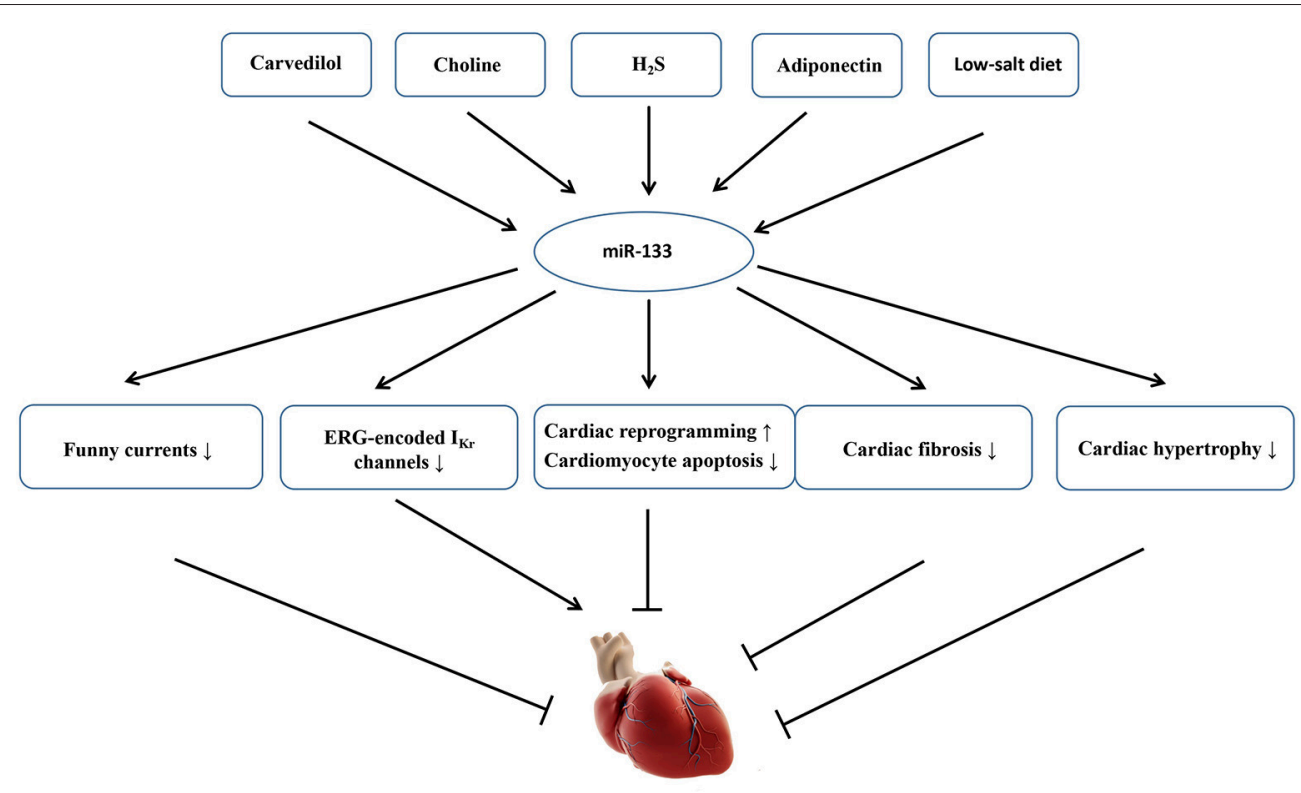

Cardiac remodelling and dysfunction

FIGURE 3 | An overview of the roles of miR-133 in cardiac remodeling as well as some endogenous and exogenous molecules that are verified to regulate miR-133 expression. Carvedilol, choline, $\mathrm{H}_{2} \mathrm{~S}$, adiponectin, and low-salt diet upregulate miR-133 expression. The increased miR-133 could inhibit cardiac fibrosis, cardiac hypertrophy, funny currents, and cardiomyocyte apoptosis and contribute to cardiac reprogram, which will mitigate cardiac dysfunction and remodeling. On the other hand, the increased miR-133 also suppresses ERG-encoded IKr channels, eventually aggravating electrical remodeling.

mRNA and directly down-regulates the expression of CTGF, the downstream molecule of TGF- $\beta /$ Smad pathway. In patients with severe valvular aortic stenosis and rodent models of pressure overload, the level of miR-133 was inversely correlated with CTGF expression (Duisters et al., 2009; Gjymishka et al., 2016). However, a high level of SRF blocked the inhibitory effect of miR-133 on CTGF expression, leading to the counteraction of the protective effect of miR-133. Intriguingly, a low level of serum response factor (SRF) promotes the protective effect of miR-133 on cardiac fibrosis (Angelini et al., 2015). The potential mechanisms warrant thorough investigation in future studies.

\section{Histone Deacetylases}

Histone acetylation/deacetylation is a vital pathway in regulating gene expression, and the balance between these modifications is mediated by histone acetyltransferases (HATs) and histone deacetylases (HDACs), respectively (Backs and Olson, 2006). Essentially, HDACs and HATs AT are the enzymes that are principally responsible for removing and adding the acetyl moiety to lysine residues of histone proteins, respectively (Lane and Chabner, 2016). Currently, the roles of HDACs in cardiac fibrosis initiation, progression as well as the therapeutic effects of HDACs inhibitors have been well investigated (AkiyamaUchida et al., 2002; Williams et al., 2014). The function of HDACs in regulating pathological cardiac remodeling was initially verified based on the interaction between class IIa HDACs and members of the myocyte enhancer factor-2 (MEF2) transcription factor family, which are critical regulators of cardiac hypertrophy. Class IIa HDACs could inhibit stress-dependent cardiac remodeling through their interaction with the MEF2 transcription factor (Konno and Seidman, 2010). Protein kinase D (PKD), a stress-responsive kinase, phosphorylates class II HDACs and promotes the dissociation of HDACs from MEF2 to induce the transcription of target genes (Fielitz et al., 2008). Hence, the PKD/class II HDACs/MEF2 axis is of critical importance in the progression of cardiac fibrosis. HDACs are present on miR-133a enhancer regions. HDAC inhibitors (Suberoylanilide Hydroxamic Acid) obviously prevent the pressure overload-induced increase in levels of the CTGF protein and collagen deposition through the interaction with deacetylation of transcription factors, co-activators or corepressors on the miR-133a enhancer and subsequent blockade of its downstream fibrotic genes (Renaud et al., 2015). Homeodomain-only protein (HOP) is a SRF co-factor that inhibits the transcriptional activity of SRF by recruiting a corepressor complex including HDACs (Kook et al., 2003). Hence, we postulate that both HOP and HDACs regulate miR-133 and may represent an innovative therapeutic approach to reset the epigenome in patients with cardiac fibrosis. Intriguingly, the effects of HDACs on cardiac fibrosis are also regulated by TGF$\beta 1$. More specifically, the TGF- $\beta 1$ treatment increases the binding of Smad2/3, Smad4 and HDAC1, and reduces the binding of acetylated histone 3 to the PPAR $\gamma$ promoter in cardiac fibroblasts (Gong et al., 2011). As mentioned above, miR-133 inhibits TGF- $\beta 1$ expression in cardiac fibroblasts to protect against cardiac fibrosis. However, researchers have not determined whether the protective effect is mediated by the inhibition of HDACs. 


\section{PI3K/Akt Pathway}

Insulin-like growth factor-1 (IGF-1), a crucial growth factor required for the proliferation, differentiation and survival of cardiomyocytes, mediates physiological cardiac hypertrophy through a PI3K-dependent pathway (Schutte et al., 2016). When tyrosine kinase receptors are bound to and activated by IGF-1 or insulins, the $\mathrm{SH} 2$ domain will recruit heterodimers of PI3K containing the regulatory subunit of PI3K, which exhibits high affinity for phosphotyrosine residues in the receptors (Aoyagi and Matsui, 2011). The current studies mainly focus on the class I PI3Ks, comprising the class IA ( $110 \alpha, \beta$, and $\delta)$ and class IB (p110 $\gamma$, encoded by $P i k 3 c g$ ) isoforms (Huang X. et al., 2016). The PI3K/Akt cascade is one of the core signaling pathways, which is usually activated upon IGF-1 receptor stimulation (Stitt et al., 2004). This pathway plays an important role in regulating glucose uptake, metabolism, protein synthesis, and proliferation, all of which share the common goal of maintaining cell survival

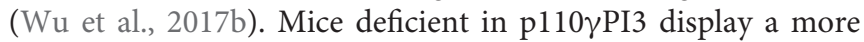
accelerated onset of HF in response to dilated or hypertrophic cardiomyopathy. An elevation in $\mathrm{p} 110 \alpha \mathrm{PI} 3 \mathrm{~K}$ activity prevents the deterioration of cardiac fibrosis and maintains cardiac function in the pressure-overload model, eventually inhibiting pathological growth (Lin et al., 2010). Previously, miR-133 has been shown to target the PI3K/Akt pathway in various human disorders. For instance, in breast cancer, miR-133a regulates the cell cycle and proliferation during tumorigenesis by targeting epidermal growth factor receptor (EGFR) through the downstream molecule Akt (Cui et al., 2013). Similarly, numerous studies have explored the roles of Akt and Akt-related serinethreonine kinases in signaling cascades that regulate multiple activities in the heart and revealed a requirement for these proteins in the pathogenesis of cardiac fibrosis (Lin et al., 2015; Ying et al., 2017). For example, upregulation of miR-133a significantly decreased in the cardiac fibrosis by inhibiting Akt in patients and rats with chronic HF (Sang et al., 2015). However, the study did not investigate miR-133 levels in cardiac fibroblasts and cardiomyocytes, respectively. Hence, further investigations are warranted to determine whether miR-133 expressed in cardiac fibroblasts or cardiomyocytes plays a leading role in inhibiting cardiac fibrosis in HF models.

\section{$\beta$-Adrenergic Receptors}

$\beta$-Adrenergic receptors ( $\beta$-ARs) belong to the $\mathrm{G}$ protein-coupled receptor family and are genetically and pharmacologically subdivided into three subtypes: $\beta_{1}, \beta_{2}$, and $\beta_{3}$ (Nakaya et al., 2012). $\beta$-ARs and their guanine nucleotide regulatory protein (G protein)-adenylyl cyclase complex play essential roles in regulating cardiac function (Najafi et al., 2016). The p38 mitogenactivated protein kinase (p38 MAPK) and reactive oxygen species (ROS) also have profound effects on cardiac fibrosis (Lu et al., 2014). The p38 MAPK cascade is activated by multiple receptors, including G-protein-coupled receptors, through the activation of protein kinases A (PKA) and PKC, thereby modulating cell proliferation and collagen synthesis (Zhang et al., 2003). In particular, cardiac fibroblast proliferation could be activated in a ROS/p38 MAPK manner, which is implicated with the production of matrix metalloproteinases (MMPs) and the fibrosis of various organs (Yu et al., 2012). The $\beta$-adrenergic system plays vital roles in inducing cardiac dysfunction and ECM remodeling, for the reason that $\beta_{2}$-AR could regulate ROS/p38 MAPK signaling pathway ( $\mathrm{Lu}$ et al., 2014). Experimental studies have validated that $\beta$-AR and its downstream components, including $\beta$-arrestin and the catalytic subunit of $3^{\prime}, 5^{\prime}$ cyclic adenosine monophosphate (cAMP)-dependent PKA, are direct targets of miR-133, which indicates that miR-133 could block the synthesis of collagen fibers by suppressing the $\beta$-AR pathway (Wang D. et al., 2017). However, researchers have not determined whether miR-133 exerts a regulatory effect on the other two MAPK signaling pathways (ERK and JNK) in cardiac fibrosis, and thus in-depth studies are required.

Based on these findings, an intricate relationship exists between miR-133 and cardiac fibrosis. Elevated miR-133 expression represses cardiac fibrosis. We propose that these findings only disclose a few functions of miR-133 in cardiac mechanical remodeling. In addition, other signaling pathways and targets related to miR-133 should be topics of further investigation.

\section{Inhibiting the Progression of Cardiac Hypertrophy}

Cardiomyocytes act as a critical role in hypertrophy and remodeling. Various types of mechanical stress and neurohumoral stimuli could increase the size and weight of cardiomyocytes, eventually leading to cardiac hypertrophy (Lyon et al., 2015). The signaling pathways involved in cardiac hypertrophy are complicated and sophisticated, including canonical pathways, such as the MAPK signaling cascade (Wu et al., 2017a), calcineurin-dependent signaling pathway (Molkentin et al., 1998), JAK/STAT signaling pathway (Kodama et al., 1997) and PI3K/Akt signaling pathway (Liu et al., 2007), and non-canonical pathways, such as the Wnt signaling pathway (Takano et al., 2002; Dolinsky et al., 2015). According to recent evidence, many miRNAs participate in the development of cardiac hypertrophy. For instance, miR-10a may markedly inhibit cardiac hypertrophy by targeting Tbx5, an important regulator of cardiac development and the cardiac cell cycle (Zhou et al., 2015; Wang D. et al., 2017). Conversely, miR451 exacerbates high-fat diet-induced cardiac hypertrophy and lipotoxicity in mouse cardiomyocytes by suppressing the serine/threonine kinase 11 (LKB1)/AMPK signaling pathway (Kuwabara et al., 2015). The expression of miR-133 displays an inverse correlation with the severity of cardiac hypertrophy in different animal models, including exercised rats, transgenic (Tg) mice with selective cardiac overexpression of a constitutively active mutant of the Akt kinase, mice treated with isoproterenol and transverse aortic arch-constricted (TAC) mice (Carè et al., 2007).

\section{MAPK}

MAPK cascades are triple kinase pathways that include a MAPK kinase (MKK), a MAPK kinase kinase (MKKK), and a terminal MAPK, which are responsible for a diverse repertoire of biological activities, including proliferation, differentiation, metabolism, motility, survival, and apoptosis (Seger and Krebs, 
1995). MAPK subfamilies have three family members, namely, cJun NH2-terminal kinases (JNK -1, -2, and -3), ERK1/2, p38 kinase $(\alpha, \beta, \gamma, \delta)$, and big MAPK (BMK or ERK5). The p38 and JNK pathways are mainly activated in response to various stresses, including infections, oxidant stress, cytokines, and osmotic shock, whereas the prototypic ERK1/2 pathway is usually activated in response to growth factor stimulation (Chang and Karin, 2001). In the heart, MAPK signaling critically regulates adaptive and maladaptive cardiac hypertrophy in response to an increased workload or pathological insults. ERK1/2 activation is involved in a beneficial form of cardiac hypertrophy that is potentially advantageous to patients with a dilated or failing heart, while p38 and JNK activation may be implicated in cardiomyopathy (Bueno et al., 2000). Cdc42, a member of the Rho subfamily (Cdc42, RhoA, and Rac1) of small GTP-binding proteins, has well-known roles in actin dynamics and is an upstream activator of MAPK (Han et al., 2017). In fibroblasts, the cell surface receptor Cdo interacts with Bnip-2, thereby activating Cdc42. Then, the activated $\mathrm{Cdc} 42$ regulates p38 MAPK activity and myogenic differentiation to link cadherin-based adhesion to the $\mathrm{p} 38 \alpha / \beta$ MAPK pathway, which enhances the muscle-specific transcriptional programme (Kang et al., 2008). Meanwhile, Cdc42 also acts as a signal transduction kinase associated with MAPK in hypertrophy. During hypertrophy, Cdc42 participates in the rearrangements of cytoskeletal and myofibrillar (Nagai et al., 2003; Liu and Molkentin, 2016). In both neonatal and adult cardiomyocytes, miR-133 overexpression or suppression could result in an elevation or a reduction in Cdc42 levels, respectively. The suppression of hypertrophic growth observed in cells cotransfected with miR-133 and a luciferase reporter gene linked to the wild-type $3^{\prime} \mathrm{UTR}$ of Cdc42 is mediated by Cdc42 silencing and the subsequently blockade of the MAPK signaling cascade (Carè et al., 2007). Intriguingly, the role of miR-133 in regulating Cdc42 expression in tumors is complex and controversial. For instance, miR-133 is an important negative regulator of $\mathrm{Cdc} 42 / \mathrm{P} 21$-activated kinases (PAK pathway) in gastric cancer by silencing Cdc42 expression, which is closely correlated with the tumor size, invasion depth and adjacent organ metastasis (Cheng et al., 2014). In contrast, miR-133 may possess an oncogenic effect and stimulate the progression of cervical carcinoma by downregulating Cdc42 and RhoA (Qin et al., 2012). Here, we hypothesize that miR-133 may also have dual functions in cardiac remodeling via the Cdc42-dependent MAPK pathway. Additionally, study showed that in cardiac hypertrophy, miR-133a might also be downregulated by Ang II through the AMPK and ERK1/2 pathways (Li et al., 2016). However, adiponectin, a cytokine that is predominantly secreted by adipose tissues, reverses hypertrophic growth partially through its positive effect on miR133a (Li et al., 2016). Furthermore, the suppressive effect of miR133 on the ERK1/2 signaling pathway in mouse myoblast cells involves an exquisite loop mechanism to regulate myogenesis. In detail, miR-133 represses myoblast proliferation and promotes cell differentiation by inhibiting ERK1/2 activation via targeting PP2AC and FGFR1, while the activated ERK1/2 pathway blocks the expression of miR-133 (Feng et al., 2013). Thus, miR-133 is a promising candidate to treat cardiac hypertrophy because of its modulatory effect on ERK1/2, which are vital proteins involved in remodeling.

\section{Calcineurin/NFAT}

Calcineurin is a member of a class of $\mathrm{Ca}^{2+}$-activated serine/threonine phosphatases that is mainly located in the cytoplasm and is modulated by calcium ions in cardiomyocytes (Taigen et al., 2000). Calcineurin was originally identified as an essential component of T lymphocyte signal transduction (Olson and Williams, 2000). In the guinea pig ventricular myocardium, calcineurin reduces the number of gap junctions and connexin levels, allowing action potentials to be propagated among cells by regulating connexin $(\mathrm{Cx} 43)$ phosphorylation at S365 and S368, eventually decreasing conductivity (Jabr et al., 2016). In the adult heart, calcineurin activity is increased, which precedes the development of pathological cardiac remodeling in response to hypertrophic or failing hearts in humans and pathological insults in mice. Upon activation by calcium ions, calcineurin dephosphorylates the transcription factor nuclear factor of activated $\mathrm{T}$ cell (NFAT), leading to nuclear translocation and subsequent hypertrophy (Sun et al., 2016; Yin et al., 2016). Calcineurin is also implicated in the endoplasmic reticulum stress response in cardiomyocyte hypertrophy and apoptosis associated with mitochondrial signaling pathway (Zaja et al., 2014). Several molecules, such as miR-133, LIM, and cysteinerich domains 1 (Lmcd1), carabin, and PPAR $\gamma$ co-activator $1 \alpha$, have been reported to regulate the calcineurin/NFAT signaling pathway during the development of adverse cardiac remodeling (Wu et al., 2017b). In HEK293 cells, the transfection of miR-133 remarkably downregulated calcineurin expression. Meanwhile, this change was reversed by cotransfection with miR-133 inhibitory oligoribonucleotides (Dong et al., 2010). NFATc4, which is one of five NFAT family members, is also one of the direct targets of miR-133a, and its expression is negatively regulated in miR-133a-mediated repression of cardiomyocyte hypertrophy in vivo (Li Q. et al., 2010). Surprisingly, the calcineurin/NFAT signaling pathway also inversely regulates miR-133 expression. Calcineurin or miR-133 could regulate their own expression through a positive feedback mechanism, and cardiac hypertrophy is regulated by the reciprocal repression between miR-133 and calcineurin (Dong et al., 2010). In detail, either exogenous miR-133 supplement or endogenous miR133 increase could give rise to the increase of transcriptional inhibition of calcineurin and suppression of NFAT, causing the increase of the miR-133 level. As a consequence, the increased miR-133 will further enchance miR-133 expression. By contrast, the downregulation of miR-133 could cause the increase of calcineurin transcription. Eventually, the activation of calcineurin induces the further activation of calcineurin/NFAT pathway (Figure 4; Dong et al., 2010).

\section{RhoA/ROCK Pathway}

Notably, c-jun and c-fos constitute two subunits of activating protein-1 (AP-1), which is a transcriptional complex required for genes expression associated with cardiac hypertrophy; therefore, the development of cardiac hypertrophy is suppressed by the negative regulation of AP-1-binding activity (Wenzel et al., 2001). 

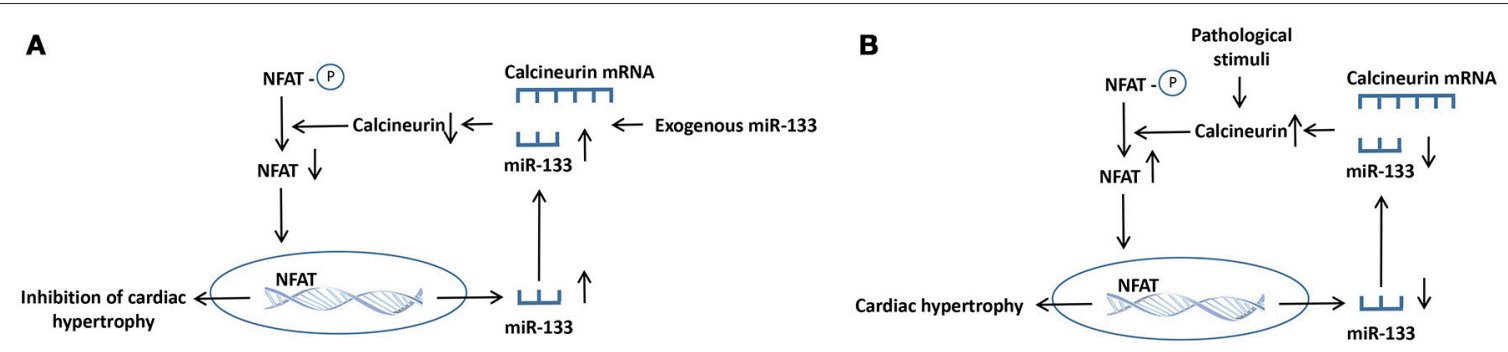

FIGURE 4 | The proposed mechanisms for the reciprocal repression between calcineurin and miR-133 in hypertrophic heart. (A) Either exogenous miR-133 supplement or endogenous miR-133 increase gives rise to the transcriptional repression of calcineurin and suppression of NFAT, causing the increased miR-133 level. Eventually, the increased miR-133 further enhanced miR-133 expression. (B) The calcineurin/ NFAT signaling is activated by pathological stimuli, giving rise to the downregulation of miR-133 expression. The decreased miR-133 induces the enhancement of calcineurin transcription. Consequently, the activated calcineurin triggers the further increase of calcineurin/ NFAT pathway. $\uparrow$, increase; $\downarrow$, decrease.

Similar to Cdc42, RhoA is also a member of the Rho subfamily of small GTP-binding proteins. The Rho-kinase (ROCK or Rhoassociated coiled-coil protein kinase) family includes ROCK1 and ROCK2, serine/threonine kinases that phosphorylate a number of downstream substrates. RhoA stimulates the expression of cjun and c-fos via ROCK and actin treadmilling, respectively $(\mathrm{Na}$ et al., 2012). The RhoA/ROCK signaling pathway participates in skeletal cell contraction and a variety of other cellular processes involving chondrogenesis and neuritogenesis by modulating the assembly of the actin cytoskeleton, which has also been confirmed to regulate cardiac hypertrophy (Yang et al., 2016; Cheng et al., 2017). In mice induced by TAC, miR-133 expression is significantly decreased in hypertrophic cardiomyocytes, and the restoration of its expression significantly represses hypertrophy through the RhoA/ROCK signaling pathway, indicating that RhoA is also a specific target of miR-133 in cardiomyocytes (Carè et al., 2007). However, the studies did not illustrate which pathway (ROCK1 or ROCK2) miR-133 affected to control hypertrophic growth because ROCK1 and ROCK2 exert relatively different physiological effects on cells. ROCK1 is required for the formation of stress fibers and the maturation of focal adhesion complexes. In contrast, ROCK2 inhibits the maturation of focal adhesions and stress fibers (Shi et al., 2013). In fibroblasts, ROCK1 knockdown leads to an absolute loss of polarity and the perturbation of peripheral actomyosin networks; however, the depletion of ROCK2 results in a clearly defined front and rear polarity (Lock et al., 2012; Newell-Litwa et al., 2015; Priya et al., 2017). Thus, further research is required to prove the hypothesis.

\section{Inositol 1,4,5-Triphosphate Receptor}

Inositol 1,4,5-triphosphate receptor $\left(\mathrm{IP}_{3} \mathrm{R}\right)$ II is a type of intracellular $\mathrm{Ca}^{2+}$ release channel that is mainly distributed in the nucleus and membrane of cardiomyocytes (Baker et al., 2017). $\mathrm{IP}_{3} \mathrm{RII}$ expression is obviously increased in hypertrophic cardiomyocytes induced by TNF- $\alpha$ and the hypertrophic, failing myocardium (Wang G. J. et al., 2017). $\mathrm{IP}_{3} \mathrm{R}$ and ryanodine receptors (RyR), but not $\mathrm{L}$ type $\mathrm{Ca}^{2+}$ channels, are the major calcium channels involved in the ectopic release of $\mathrm{Ca}^{2+}$ from intracellular $\mathrm{Ca}^{2+}$ stores in the sarcoplasmic reticulum. The ectopic $\mathrm{Ca}^{2+}$ released from these receptors induces the expression of pro-hypertrophic genes and may cause arrhythmias, playing important roles in the remodeling mechanisms (Sankar et al., 2014; Wang D. et al., 2017). MiR133a constitutively restrains the expression of $\mathrm{IP}_{3} \mathrm{RII}$ during the hypertrophic response to neurohormonal stimuli or pressure overload, potentially promoting the physiological growth of cardiomyocytes until the balance between $\mathrm{IP}_{3} \mathrm{RII}$ and miR-133a is upset by pathological stimuli that could trigger inositol 1,4,5triphosphate receptor $\left(\mathrm{IP}_{3}\right)$-induced calcium release (IICR). Intriguingly, when IICR is engaged in this fashion, sustained repression of miR-133a promoted by enhanced IICR generates a deleterious positive feedback loop, providing a powerful driving force for pathological cardiac remodeling (Figure 5; Drawnel et al., 2012). Briefly, miR-133a is promising target to protect against pro-hypertrophic transcriptional responses mediated by IICR because it inhibits $\mathrm{IP}_{3} \mathrm{RII}$ expression and IICR.

\section{PI3K/AKT Signaling Pathway}

The preceding section has elaborated the vital importance and mechanisms by which the PI3K signaling pathway participates in the development of cardiac fibrosis. In fact, in addition to the effects on cardiac fibrosis, the PI3K pathway plays more important and essential roles in regulating cardiomyocyte survival, cardiomyocyte size, angiogenesis, and inflammation during physiological and pathological cardiac hypertrophy (Braz et al., 2014).

Distinct signaling mechanisms associated with IGF-1-induced hypertrophy require Akt and its downstream molecules GSK$3 \beta$ and mTOR. Overexpression of either IGF receptor or IGF1 activates PI3K ( $110 \alpha)$ will result in physiological cardiac hypertrophy and even MI, while a PI3K (p110 $\gamma$ ) deficiency prevents HF induced by isoproterenol (Aoyagi and Matsui, 2011). In the mouse model, an IGF-1 deficiency protects against abdominal aortic constriction-induced cardiac hypertrophy by dampening Akt signaling and glucose transporter 4 (GLUT4) levels. However, overexpression of miR-133a and miR-1 also abrogates IGF-1-mediated cardiomyocyte hypertrophy and cardiac dysfunction (Hua et al., 2012). In addition, miR-133a directly targets AKT and alleviates cardiac hypertrophy by 


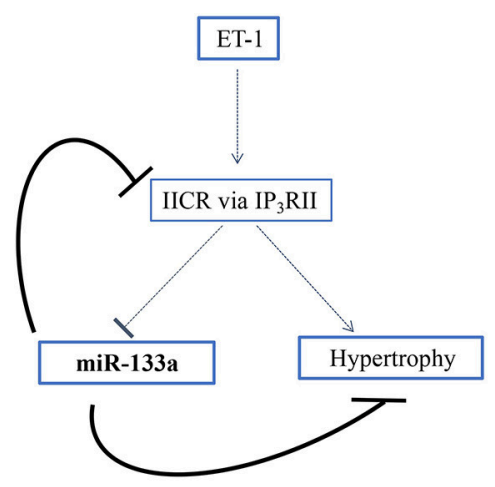

Baseline condationa: Cell growth restricted

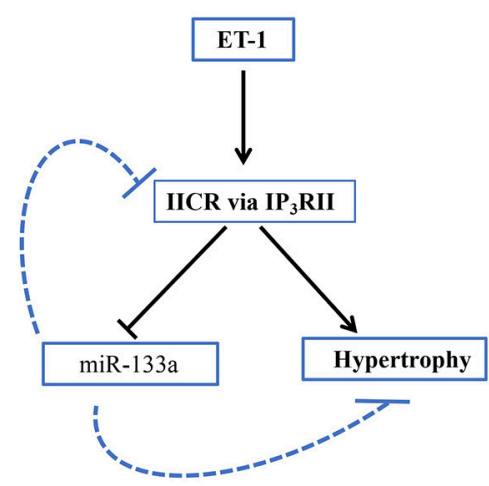

Pathological condition: Pro-hypertrophic remodeling

calcium homeostasis and transcription

FIGURE 5 | IICR participates in a pro-hypertrophic positive feedback loop. Schematic showing how the loss of miR-133a-mediated IP3R\|ll inhibition generates a positive feedback loop to drive the hypertrophic response (Drawnel et al., 2012).

inhibiting the synthesis of translation-related proteins associated with hypertrophy by blocking PI3k/AKT/(mTOR, GSK3 $\beta$ ) (Sang et al., 2015). However, because of the multiple downstream effectors in the PI3K signaling pathway and the diverse pathophysiological characteristics of hypertrophy, further studies are required to develop effective therapeutic approaches based on miR-133.

\section{$\beta$-Adrenergic Receptors}

The most effective mechanism to improve cardiac output in response to exercise or stress is to stimulate cardiomyocyte adrenergic receptors with noradrenaline released from the sympathetic nervous system (Charkoudian et al., 2010). The cAMP-dependent PKA signaling pathway primarily mediates the positive chronotropic, inotropic, and lusitropic effects of cAMP on cardiomyocytes, aiming to phosphorylate and modulate a number of core proteins involved in cardiac excitationcontraction coupling (Parks et al., 2017). In cardiac hypertrophy, chronically increased catecholamine levels induce cardiac $\beta$ AR signaling to desensitize the heart, accompanied by a reduction in cAMP-cyclic nucleotide phosphodiesterase and altered modulation of the $\beta$-AR/cAMP signaling pathway (AbiGerges et al., 2009). Similar to fibrosis, miR-133 also exerts a favorable effect on inhibiting $\beta$-AR in cardiomyocytes, the mechanisms of which may be related to the $\beta$-AR/ERK1/2 and cAMP signaling pathways (Wang D. et al., 2017). Additionally, the associations of miR-1/miR-133a, cAMP signaling pathway, hypertrophy and electrical remodeling were also evaluated in the mouse model of MI. Enhanced expression of the cAMP early repressor suppressed the expression of miR-1 and miR-133a, leading to hypertrophy and electrical remodeling, respectively. Meanwhile, by delivering miR-1 and miR-133a in vivo, inducible cAMP early repressor expression was blocked so that both hypertrophy and electrical remodeling were alleviated (Myers et al., 2015). Therefore, feedback mechanisms for cardiac-specific
miR133a, miR-1, and cAMP signaling pathways exist in cardiac hypertrophy and electrical remodeling, providing proof-ofconcept for the potential applications of miR-1 and miR-133a therapy for MI. However, in contrast to the aforementioned results, another study found that postnatal overexpression of miR-133a in cardiomyocytes does not affect reactive cardiac hypertrophy induced by isoproterenol or pressure overload, although it alleviates cardiac fibrosis (Matkovich et al., 2010). From our perspective, the possible explanations for the discrepancies in these results are mainly attributed to the use of different conceptual approaches in experimental models, the developmental stage at which miR-133a is expressed, and the time-point when samples are collected from transgenic models. For example, one study halted the normal downregulation of miR-133a in an acute hypertrophic stimulus model but did not completely knock out miR-133.

The links between these hypertrophy-related miRNAs and corresponding targets or signaling pathways were briefly summarized (Figure 6). After considering all findings presented in this section, we postulate that miR-133 is very likely to suppress cardiac hypertrophy. The links between these hypertrophyrelated miRNAs and corresponding targets or signaling pathways are highly complex. Hence, we may only be able to verify crucial regulatory nodules that can be manipulated to affect the outcomes by concentrating on network interactions rather than the signaling molecules themselves.

\section{A Double-Edged Sword in Cardiac Electrical Remodeling}

Electrophysiological remodeling in $\mathrm{HF}$ and $\mathrm{AF}$ involves alterations in both the active membrane properties of heart cells and network attributes of the myocardium, which displays the hallmarks of prolonged action potential duration (APD) and slower conduction (John et al., 2008; Walmsley et al., 2013). The main pathogenesis resulting in prolonged APD and slower 


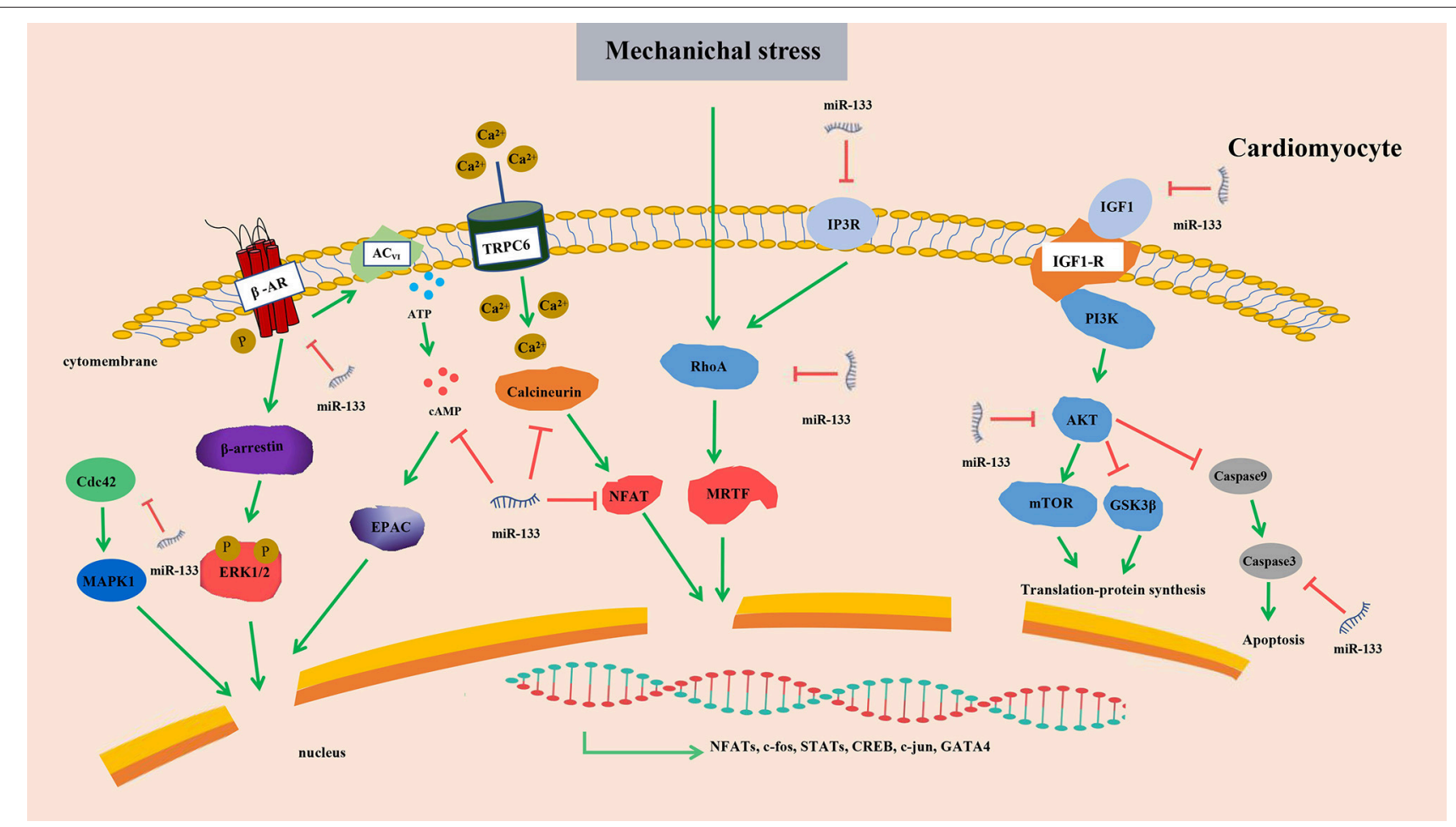

FIGURE 6 | Targets of miR-133 in cardiomyocytes. Upregulated miR-133 inhibits the expression of $\beta$-AR, cAMP, Cdc42, AKT, Calcineurin, IP3R, RhoA, IGF1, and Caspase 3 and contribute to the activity of transcription factors, resulting in cardiac hypertrophy. $\beta$-AR, $\beta$-adrenergic receptor transduction; cAMP, $3^{\prime}, 5^{\prime}$ cyclic adenosine monophosphate; AKT, serine/threonine kinase; InoIP3R, sitol 1,4,5-triphosphate receptor; IGF-1, Insulin-like growth factor-1; MAPK, mitogen-activated protein kinase; ERK, extracellular signal-regulated kinases; EPAC, exchange protein directly activated by CAMP; NFAT, nuclear factor of activated T cell; mTOR, mammalian target of rapamycin; TRPC6, transient receptor potential 6; MRTF, myocardin-related transcription factor A; GSK3 $\beta$, Glycogen synthase kinase-3 $\beta$; Red arrows, suppression; green arrows, promotion.

conduction include the downregulation of $\mathrm{K}^{+}$currents and changes in depolarizing $\mathrm{Na}^{+}$and $\mathrm{Ca}^{+}$currents and transporters (Aslani et al., 2016). As the interactions between miRNAs and cardiac electrical remodeling are gradually unveiled, more and more miRNAs are being explored. For instance, miR-328 contributes to the adverse atrial electric remodeling in $\mathrm{AF}$, the mechanism of which may be mediated by targeting L-type $\mathrm{Ca}^{2+}$ channel genes such as CACNA1C and CACNB1 (Lu et al., 2010). In cardiomyocytes from patients with persistent $A F$, the expression of predicted targets of miR-30d, including CACNA1C encoding Cav1.2 and KCNJ3 encoding Kir3.1, are also decreased, subsequently reducing the acetylcholine-sensitive inwardrectifier $\mathrm{K}^{+}$current (Morishima et al., 2016). Currently, the relationship between miR-133 and cardiac electrical remodeling remains unclear, and controversy exists regarding whether miR-133 promotes or inhibits electrical remodeling.

Repolarization is modulated by a delicate balance between the inward and outward currents in cardiomyocyte membrane (Schroder et al., 2015). $\mathrm{I}_{\mathrm{Kr}}$ and $\mathrm{I}_{\mathrm{K} 1}$, two key repolarizing currents, are mainly responsible for the repolarization of the membrane potential, which were mediated by the $\mathrm{K}^{+}$channel subunits encoded by KCNJ2 and Ether-a-go-go related gene (ERG), respectively (Georgieva et al., 2008; Park et al., 2013). In the diabetic hearts, miR-133a regulates the expression of the
ERG-encoded $\mathrm{I}_{\mathrm{Kr}}$ channel, resulting in synchronous alterations at levels of the ERG mRNA and protein. The miR-133mediated suppression of the ERG-encoded $\mathrm{I}_{\mathrm{Kr}}$ channels leads to pathological QT prolongation. In this process, the level of miR-133 was also regulated by its upstream modulator SRF, which constituted a hyperglycaemia/SRF/miR-133/ERG/I $\mathrm{Kr}$ axis to modulate the current in cardiomocytes (Xiao et al., 2011). Under some certain pathological conditions, such as arsenic trioxide $\left(\mathrm{As}_{2} \mathrm{O}_{3}\right)$ exposure, $\mathrm{I}_{\mathrm{Kr}}$ and $\mathrm{I}_{\mathrm{K} 1}$ may be blocked and contribute to a prolonged $\mathrm{APD}$ and $\mathrm{QT}$ interval (Chiang et al., 2002). A remarkable up-regulation of miR-1 and miR133 was observed in the guinea pig model of $\mathrm{As}_{2} \mathrm{O}_{3}$-induced QT prolongation. The transfer of miR-133 into normal pig cardiomyocytes via a direct intramuscular injection prolonged the QT interval and increased the animals' mortality. Meanwhile, the expression of both the ERG protein and $\mathrm{I}_{\mathrm{Kr}}$ was inhibited. Obviously, $\mathrm{As}_{2} \mathrm{O}_{3}$-induced cardiotoxicity in guinea pig hearts, including $\mathrm{AF}$ and sudden cardiac death, may be mediated by the upregulation of miR-133 and the inhibition of ERG and Kir2.1 $\mathrm{K}^{+}$channel at the post-transcriptional level. The proposed molecular pathway is $\mathrm{As}_{2} \mathrm{O}_{3} / \mathrm{SRF} / \mathrm{miR}-133 /(\mathrm{KCNH} 2, \mathrm{ERG}$, and $\left.\mathrm{I}_{\mathrm{Kr}}\right) /(\mathrm{APD}$ and QT prolongation)/sudden cardiac death (Shan et al., 2013). In the clinic, plasma miR-133 levels in pediatric patients with ventricular tachycardia are obviously increased 
compared with normal children, which may also be attributed to damage to these repolarization current channels (Sun et al., 2015). However, further investigations are needed to validate this hypothesis.

Nevertheless, miR-133 has also been reported to exert a protective effect on cardiac electrical remodeling. Hyperpolarization-activated non-specific cation channels (HCNs) conduct a mixed $\mathrm{K}^{+} / \mathrm{Na}^{+}$depolarizing current, which is activated by cAMP and hyperpolarization. Once the HCNs are activated in the myocardial diastolic period, membrane depolarization is triggered immediately (Myers et al., 2015; Wen and $\mathrm{Li}, 2017$ ). In the right atrial appendage from patients with AF, the levels of HCN2 and HCN4 channels are significantly increased, accompanied by a decrease in miR-133 and miR-1 levels with aging. The mechanisms underlying this phenomenon may be that miR-133 and miR-1 exert inhibitory effects on HCN2 and HCN4 which could enhance the funny current and increase the incidence of atrial tachycardia and premature ventricular beats (Li et al., 2015). However, the protective mechanisms and targets of miR-133 were not extensively investigated in this study. What is more, by preventing the downregulation of miR-133a in a mouse model of TAC-induced cardiac remodeling, the downregulation of $\mathrm{Kv} 4$-encoded $\mathrm{I}_{\text {to, } \mathrm{f}}$ was abolished despite the presence of abnormal repolarization, because miR-133 potentially enhanced the expression of Kv4-encoded $\mathrm{I}_{\text {to,f }}$ (Kcnip2), whose upregulation may decrease the content of collagen in fibroblasts and prevent abnormal $\mathrm{I}_{\text {to,f }}$ (Matkovich et al., 2010).

This section mainly generalizes the dual effects of miR-133 on cardiac electrical remodeling. We presume that miR-133 acts as a double-edged sword by activating or repressing the expression of different genes encoding membrane electrical channels. The number and activity of electrical channels directly determine the protective or destructive role in cardiac remodeling. Meanwhile, due to the complexity and specificity of the signal transduction network, the verification of any molecules as absolutely "good" or "bad" is imprudent and impossible. Hence, the precise mechanisms require further investigation.

\section{Promoting Cardiac Reprogram and Maintaining Cardiomyocytes}

Cardiomyocytes with normal physiological functions are essential and critical to the heart, but in the failing heart, the number of normal cardiomyocytes is limited (Massengill et al., 2016). Thus, researchers have utilized numerous approaches to generate new cardiomyocytes, such as transplanting stem cells or inducing their differentiation (Zwi-Dantsis et al., 2013). MiRNAs are a group of intriguing candidates to regulate heart regeneration, given their abilities to simultaneously influence various mRNA targets (Eulalio et al., 2012). The upregulation of some cardiac-specific transcription factors and miR-133 in the heart can help to reprogram cardiac fibroblasts into cardiomyocyte-like cells (iCMs) with functional properties such as spontaneous calcium oscillations, L-type channel expression, and contractility (Muraoka et al., 2014). In mouse embryonic fibroblasts, the overexpression of miR-133 and Tbx5 generated seven-fold more beating iCMs and reduced the time to induce beating cells from 30 to 10 days compared with cells in which Tbx5 was up-regulated alone. In this reprogram process, miR-133 directly represses the expression of Snail, a master regulator of the EMT. Intriguingly, this process by which the miR-133/Snail pathway silences fibroblast signatures is similar to the mesenchymal-to-epithelial transition (MET), a vital step in the reprogram of fibroblasts into induced pluripotent stem cells (iPSCs) by Yamanaka factors (Li R. et al., 2010; Samavarchi-Tehrani et al., 2010). Additionally, a combination of miR-133 and JAK inhibitor I treatment exhibits a significant improvement in efficiency by enhancing either the expression of cardiac ion channels or $\alpha$-MHC (Jayawardena et al., 2012). Mesenchymal stem cells (MSCs) are a class of pluripotent, adult stem cells that are easily expanded in culture and can differentiate into several mesenchymal cell lineages, including vascular endothelial cells and iCMs (Soleymaninejadian et al., 2015). In the ischaemic microenvironment of the heart, the transfection of miR-133a in MSCs significantly improves MSC survival and engraftment by inhibiting the expression of the Caspase-9 and Apaf-1 mRNAs, subsequently resulting in decreased cell apoptosis and cardiac fibrosis and improved cardiac function (Dakhlallah et al., 2015). Furthermore, in cardiac progenitor cells (CPCs) obtained from adult mouse hearts, miR-133a overexpression protected CPCs from apoptosis and increased their capacity to inhibit hypertrophy by targeting the proapoptotic genes $\mathrm{Bmf}$ and Bim, but the proliferation and differentiation potential were not affected (Izarra et al., 2014).

In $\mathrm{H} 9 \mathrm{c} 2$ cells, miR-133 and miR-1 exert opposite regulatory effects on cardiomyocyte apoptosis induced by oxidative stress. When miR-1 and miR-133 were co-transfected into cardiomyocytes, oxidative stress-induced apoptosis was not affected. However, in the presence of oxidative stress, the levels of miR-133 and miR-1 were both markedly increased compared to cells that were not exposed to oxidative stress. Notably, a substantially greater increase in miR-1 expression was observed than in miR-133 levels, indicating miR-133 is an anti-apoptotic factor while miR-1 is a pro-apoptotic factor. The underlying mechanism is probably that miR133 targets Caspase 9 and miR-1 targets heat shock protein (HSP) 60 and HSP70 to inhibit apoptosis (Xu et al., 2007; Friedrich et al., 2015). Similarly, in a rat model of ischaemiareperfusion injury, ischaemic post-conditioning protects against cardiomyocyte apoptosis by upregulating miR-133 to target the caspase cascade-mediated apoptotic pathway (He et al., 2011).

Notably, miR-133a-deficient hearts display increased and aberrant cardiomyocyte proliferation throughout the atria and ventricles, which potentially explains the development of a lethal ventricular septal defect in miR-133 knockout mice (Liu et al., 2008). Liu et al. investigated the cardiac transcriptome of miR133a knockout hearts to identify the mechanism by which miR133a regulates cardiomyocyte proliferation and confirmed the up-regulation of several transcription factors involved in cell cycle control, namely, Cyclin D1, Cyclin D2, and Cyclin B1. Among these factors, Cyclin D2 contained a miR-133a seed 
sequence in its $3^{\prime}$-UTR, indicating that Cyclin D2 may serve as a direct target of miR-133 (Liu et al., 2008). Consistent with findings from mammals, in a zebrafish model subjected to heart resection surgery, miR-133 inhibited cardiomyocyte proliferation by modulating the activity of monopolar spindle 1 (Mps1) and $\mathrm{Cx} 43$. However, in the absence of cardiac injury, cardiomyocyte proliferation was not influenced significantly, regardless of the expression levels of miR-133 (Yin et al., 2012). Furthermore, miR133 also plays a key inhibitory role in the vascular smooth muscle cell phenotypic switch by suppressing the expression of the transcription factor $\mathrm{Sp}-1$ in vitro and in vivo. In this regulatory pathway, the level of miR-133 was determined by extracellular signal-regulated kinase 1/2 activation (Torella et al., 2011).

Taken together, an HF therapy must maintain the normal proportion and functions of cardiomyocytes in the heart. Gratifyingly, cardiac fibroblasts that have been reprogrammed into iCMs and stem cells show a promising future in cardiomyocyte regeneration. Hence, further studies are needed to explore the precise mechanisms underlying the functions of miR-133 in reprogram.

In addition to its direct cardioprotective effects mediated by the four mechanisms discussed throughout this review, miR-133 is also linked to energy balance and might indirectly prevent cardiac remodeling. For instance, miR-133 could decide the cell commitment between brown adipocytes and myocytes by targeting Prdm16, indicating that miR-133 may be a promising therapeutic target for diabetic cardiomyopathy associated with obesity (Trajkovski et al., 2012).

\section{DIAGNOSTIC AND THERAPEUTIC POTENTIAL OF MIR-133 IN CARDIAC REMODELING: FUTURE PERSPECTIVES}

Over the last several years, several studies conducted using animal models have uncovered revealed the potential of miRNAs for the diagnosis and treatment of a vast array of diseases, ranging from cardiovascular diseases to neurological diseases and cancer ( $\mathrm{Lu}$ et al., 2008). For instance, in patients with HF undergoing the implantation of a left ventricular assist device, reduced serum miR-133a levels are significantly associated with increased Beclin 1, LC3B, and ATG3 expression, thus resulting in the exacerbation of diabetes-induced cardiac autophagy and hypertrophy (Nandi et al., 2015). In surgical patients with coronary artery disease, decreased expression of miR-133 also significantly correlates with an increased severity of $\mathrm{HF}$ (Danowski et al., 2013). Lower miR-133 levels have been detected in peripheral blood mononuclear cells $(10.16 \pm 4.81$ vs. 37.03 $\pm 8.18, p<0.05)$ from patients with left ventricle diastolic dysfunction compared with the healthy controls (Marketou et al., 2013). Actually, in addition to stressing the excellent potential of miRNAs as biomarkers of cardiovascular diseases, several studies have also highlighted new challenges and possibilities for the development of innovative therapeutic strategies using either transgenic or gene deletion approaches. One strategy is to utilize exogenous drugs to restore or suppress the expression of miR133 by regulating the activity of its upstream and downstream molecules. Currently, certain drugs with preclinical relevance have been already proven to regulate miR-133 expression both in vitro and in vivo. For example, carvedilol protects cardiomyocytes from $\mathrm{H}_{2} \mathrm{O}_{2}$-induced apoptosis by up-regulating miR-133, although the study did not provide any insights into the mechanism by which carvedilol regulated miR-133 levels in response to oxidative stress (Xu et al., 2014). Additionally, a choline supplement inhibited TAC-induced cardiac hypertrophy by restoring the abnormally downregulated expression of miR133a and the calcineurin protein (Zhao et al., 2013). Moreover, HOP, histone deacetylases and the JAK inhibitor mentioned above are also promising drugs for resetting the epigenome and reprogram cardiac remodeling. The intake of a highsalt diet might result in cardiac fibrosis in individuals with salt-sensitive hypertension by suppressing miR-133a expression; therefore, the intake of a low-salt diet, in essence, is also an exogenous regulator of miR-133 expression (Guo et al., 2014). Additionally, other endogenous and exogenous molecules, such as adiponectin (Abi-Gerges et al., 2009) and hydrogen sulfide $\left(\mathrm{H}_{2} \mathrm{~S}\right)$ (Mishra et al., 2012), have also been shown to upregulate miR-133 in the heart to protect against cardiac hypertrophy and diabetic cardiomyopathy. Another strategy, which may be the most advanced and feasible therapeutic strategy (at least in experimental animal models), is to employ miR133 mimic or its antagonist as molecular drugs to directly target corresponding genes and proteins involved in cardiac remodeling. Although substantial progress has been achieved in miRNA-based therapeutics, researchers are still confronted with several issues with the precise delivery of drugs to the heart and the efficient targeting of specific cell populations. Further investigations are required to prevent the degradation of synthetic miR-133 and to determine its pharmacokinetics and pharmacodynamics in the human body. Therefore, we conjecture that the clinical applications of vector-based gene therapy for cardiac remodeling will be likely to be introduced in the very near future.

\section{CONCLUSIONS}

In this review, we described the roles and mechanisms of miR133 in cardiac remodeling, which might be beneficial references for clinical applications and future investigations. Importantly, miR-133 inhibits the progression of cardiac hypertrophy and cardiac fibrosis, promotes the reprogram of cardiac fibroblasts into iCMs, improves MSC survival and represses CPC apoptosis, all of which indicate that miR-133 serves as a weapon against cardiac remodeling. Intriguingly, miR-133 may act as a doubleedged sword in cardiac electrical remodeling. It alleviates arrhythmia by regulating the expression of some ion channels; meanwhile, it also aggravates electrical activity disorders, causing $\mathrm{AF}$ and sudden death. Thus, miR-133 functions through diverse target genes and sophisticated signaling pathways in cardiac remodeling, including RhoA, Cdc42, HERG, and PI3K/Akt signaling pathways. Although numerous investigations are exploring the relationship between miR-133 and various cardiac disorders, we hypothesize that additional potential target genes and molecular pathways of miR-133 will be identified in subsequent investigations. 
More empirical data pertaining to the improvements in cardiac function and the safety and efficacy of various HF models are required before miR-133 is translated from the bench to the bedside. We sincerely hope that this review provides some insights into future clinical applications and further studies.

\section{AUTHOR CONTRIBUTIONS}

NL was responsible for conceiving and designing the review and writing the manuscript. HZ was in charge of conceiving

\section{REFERENCES}

Abi-Gerges, A., Richter, W., Lefebvre, F., Mateo, P., Varin, A., Heymes, C., et al. (2009). Decreased expression and activity of cAMP phosphodiesterases in cardiac hypertrophy and its impact on beta-adrenergic cAMP signals. Circ. Res. 105, 784-792. doi: 10.1161/CIRCRESAHA.109.197947

Aguilar, M., Qi, X. Y., Huang, H., and Nattel, S. (2014). Fibroblast electrical remodeling in heart failure and potential effects on atrial fibrillation. Biophys. J. 107, 2444-2455. doi: 10.1016/j.bpj.2014.10.014

Akiyama-Uchida, Y., Ashizawa, N. A., Seto, S., Tsukazaki, T., Kikuchi, H., Yamashita, S., et al. (2002). Norepinephrine enhances fibrosis mediated by TGF-beta in cardiac fibroblasts. Hypertension 40, 148-154. doi: 10.1161/01.HYP.0000025443.61926.12

Angelini, A., Li, Z., Mericskay, M., and Decaux, J. F. (2015). Regulation of connective tissue growth factor and cardiac fibrosis by an SRF/MicroRNA-133a axis. PLoS ONE 10:e0139858. doi: 10.1371/journal.pone.0139858

Aoyagi, T., and Matsui, T. (2011). Phosphoinositide-3 kinase signaling in cardiac hypertrophy and heart failure. Curr. Pharm. Des. 17, 1818-1824. doi: $10.2174 / 138161211796390976$

Aslani, A., Khajei, M., Shahrzad, S., Nikoo, M. H., Jorat, M. V., and Bigi, M. A. (2016). Effect of cardiac resynchronisation therapy on electrical remodelling. Heart Lung Circ. 25, 471-475. doi: 10.1016/j.hlc.2015.10.014

Backs, J., and Olson, E. N. (2006). Control of cardiac growth by histone acetylation/deacetylation. Circ. Res. 98, 15-24. doi: 10.1161/01.RES.0000197782.21444.8f

Baker, M. R., Fan, G., and Serysheva, I. I. (2017). Structure of IP3R channel: high-resolution insights from cryo-EM. Curr. Opin. Struct. Biol. 46, 38-47. doi: 10.1016/j.sbi.2017.05.014

Bernardo, B. C., Weeks, K. L., Pretorius, L., and McMullen, J. R. (2010). Molecular distinction between physiological and pathological cardiac hypertrophy: experimental findings and therapeutic strategies. Pharmacol. Ther. 128, 191-227. doi: 10.1016/j.pharmthera.2010.04.005

Braz, J. C., Gill, R. M., Corbly, A. K., Jones, B. D., Jin, N., Vlahos, C. J., et al. (2014). Selective activation of PI3Kalpha/Akt/GSK-3beta signalling and cardiac compensatory hypertrophy during recovery from heart failure. Eur. J. Heart Fail. 11, 739-748. doi: 10.1093/eurjhf/hfp094

Bueno, O. F., Windt, L. J. D., Tymitz, K. M., Witt, S. A., Kimball, T. R., Klevitsky, R., et al. (2000). The MEK1-ERK1/2 signaling pathway promotes compensated cardiac hypertrophy in transgenic mice. EMBO J. 19, 6341-6350. doi: 10.1093/emboj/19.23.6341

Calin, G. A., and Croce, C. M. (2006). MicroRNA signatures in human cancers. Nat. Rev. Cancer 6, 857-866. doi: 10.1038/nrc1997

Carè, A., Catalucci, D., Felicetti, F., Bonci, D., Addario, A., Gallo, P., et al. (2007). MicroRNA-133 controls cardiac hypertrophy. Nat. Med. 13, 613-618. doi: $10.1038 / \mathrm{nm} 1582$

Castoldi, G., Di, G. C., Bombardi, C., Catalucci, D., Corradi, B., Gualazzi, M. G., et al. (2012). MiR-133a regulates collagen 1A1: potential role of miR-133a in myocardial fibrosis in angiotensin II-dependent hypertension. J. Cell. Physiol. 227, 850-856. doi: $10.1002 /$ jcp. 22939

Chamberlain, A. M., St Sauver, J. L., Gerber, Y., Manemann, S. M., Boyd, C. M., Dunlay, S. M., et al. (2015). Multimorbidity in heart failure: a community perspective. Am. J. Med. 128, 38-45. doi: 10.1016/j.amjmed.2014.08.024 and designing some portions of the review and writing the manuscript. HZ reviewed and edited the manuscript. QT was the principal investigator of this study and serves as the corresponding author.

\section{FUNDING}

This work was supported by grants from the National Natural Science Foundation of China (Nos. 81470516, 81530012, 81300070, and 81770399) and the Fundamental Research Funds for the Central Universities of China (2042018kf0121).

Chang, L., and Karin, M. (2001). Mammalian MAP kinase signalling cascades. Nature 410, 37-40. doi: 10.1038/35065000

Charkoudian, N., Joyner, M. J., Johnson, C. P., Eisenach, J. H., Dietz, N. M., and Wallin, B. G. (2010). Balance between cardiac output and sympathetic nerve activity in resting humans: role in arterial pressure regulation. J. Physiol. 568, 315-321. doi: 10.1113/jphysiol.2005.090076

Chen, J. F., Mandel, E. M., Thomson, J. M., Wu, Q., Callis, T. E., Hammond, S. M., et al. (2006). The role of microRNA-1 and microRNA-133 in skeletal muscle proliferation and differentiation. Nat. Genet. 38, 228-233. doi: 10.1038/ ng1725

Chen, S., Puthanveetil, P., Feng, B., Matkovich, S. J., Nd, D. G., and Chakrabarti, S. (2014). Cardiac miR-133a overexpression prevents early cardiac fibrosis in diabetes. J. Cell. Mol. Med. 18, 415-421. doi: 10.1111/jcmm.12218

Chen, X., Bai, Y., Sun, H., Su, Z., Guo, J., Sun, C., et al. (2017). Overexpression of M3 muscarinic receptor suppressed adverse electrical remodeling in hypertrophic myocardium via increasing repolarizing $\mathrm{K}+$ currents. Cell. Physiol. Biochem. 43, 915-925. doi: 10.1159/000481642

Cheng, C. I., Lee, Y. H., Chen, P. H., Lin, Y. C., Chou, M. H., and Kao, Y. H. (2017). Cobalt chloride induces RhoA/ROCK activation and remodeling effect in $\mathrm{H} 9 \mathrm{c} 2$ cardiomyoblasts: involvement of PI3K/Akt and MAPK pathways. Cell. Signal. 36, 25-33. doi: 10.1016/j.cellsig.2017.04.013

Cheng, Z., Liu, F., Wang, G., Li, Y., Zhang, H., and Li, F. (2014). miR-133 is a key negative regulator of CDC42-PAK pathway in gastric cancer. Cell. Signal. 26, 2667-2673. doi: 10.1016/j.cellsig.2014.08.012

Chiang, C. E., Luk, H. N., Wang, T. M., and Ding, P. Y. (2002). Prolongation of cardiac repolarization by arsenic trioxide. Blood 100, 2249-2252. doi: 10.1182/blood-2002-02-0598

Ciccacci, C., Rufini, S., Politi, C., Novelli, G., Forte, V., and Borgiani, P. (2015). Could MicroRNA polymorphisms influence warfarin dosing? A pharmacogenetics study on mir133 genes. Thromb. Res. 136, 367-370. doi: 10.1016/j.thromres.2015.06.026

Cohn, J. N., Ferrari, R., and Sharpe, N. (2000). Cardiac remodeling-concepts and clinical implications: a consensus paper from an international forum on cardiac remodeling. Behalf of an International Forum on Cardiac Remodeling. J. Am. Coll. Cardiol. 35, 569-582. doi: 10.1016/S0735-1097(99)00630-0

Courboulin, A., Paulin, R., Giguère, N. J., Saksouk, N., Perreault, T., Meloche, J., et al. (2011). Role for miR-204 in human pulmonary arterial hypertension. J. Exp. Med. 208, 535-548. doi: 10.1084/jem.20101812

Cui, W., Zhang, S., Shan, C., Zhou, L., and Zhou, Z. (2013). microRNA-133a regulates the cell cycle and proliferation of breast cancer cells by targeting epidermal growth factor receptor through the EGFR/Akt signaling pathway. FEBS J. 280, 3962-3974. doi: 10.1111/febs.12398

Da Costa Martins, P., and De Windt, L. J. (2012). MicroRNAs in control of cardiac hypertrophy. Cardiovasc. Res. 93, 563-572. doi: 10.1093/cvr/cvs013

Dakhlallah, D., Zhang, J., Yu, L., Marsh, C. B., Angelos, M. G., and Khan, M. (2015). MicroRNA-133a engineered mesenchymal stem cells augment cardiac function and cell survival in the infarct heart. J. Cardiovasc. Pharmacol. 65, 241-251. doi: 10.1097/FJC.0000000000000183

Danowski, N., Manthey, I., Jakob, H. G., Siffert, W., Peters, J., and Frey, U. H. (2013). Decreased expression of miR-133a but not of miR-1 is associated with signs of heart failure in patients undergoing coronary bypass surgery. Cardiology 125, 125-130. doi: 10.1159/000348563 
Dijke, P. T., and Hill, C. S. (2004). New insights into TGF- $\beta$-Smad signalling. Trends Biochem. Sci. 29, 265-273. doi: 10.1016/j.tibs.2004.03.008

Dolinsky, V. W., Soltys, C. L. M., Rogan, K. J., Chan, A. Y. M., Nagendran, J., Wang, S., et al. (2015). Resveratrol prevents pathological but not physiological cardiac hypertrophy. J. Mol. Med. 93, 413-425. doi: 10.1007/s00109-0141220-8

Dong, D. L., Chen, C., Huo, R., Wang, N., Li, Z., Tu, Y. J., et al. (2010). Reciprocal repression between microRNA-133 and calcineurin regulates cardiac hypertrophy: a novel mechanism for progressive cardiac hypertrophy. Hypertension 55, 946-952. doi: 10.1161/HYPERTENSIONAHA.109. 139519

Drawnel, F. M., Wachten, D., Molkentin, J. D., Maillet, M., Aronsen, J. M., Swift, F., et al. (2012). Mutual antagonism between IP3RII and miRNA-133a regulates calcium signals and cardiac hypertrophy. J. Cell Biol. 199, 783-798. doi: $10.1083 /$ jcb.201111095

Duisters, R. F., Tijsen, A. J., Schroen, B., Leenders, J. J., Lentink, V., Made, I. V. D., et al. (2009). miR-133 and miR-30 regulate connective tissue growth factor Implications for a role of MicroRNAs in myocardial matrix remodeling. Circ. Res. 104, 170-178. doi: 10.1161/CIRCRESAHA.108.182535

Eulalio, A., Mano, M., Dal, F. M., Zentilin, L., Sinagra, G., Zacchigna, S., et al. (2012). Functional screening identifies miRNAs inducing cardiac regeneration. Nature 492, 376-381. doi: 10.1038/nature11739

Feng, Y., Niu, L. L., Wei, W., Zhang, W. Y., Li, X. Y., Cao, J. H., et al. (2013). A feedback circuit between miR-133 and the ERK1|[sol]|2 pathway involving an exquisite mechanism for regulating myoblast proliferation and differentiation. Cell Death Dis. 4:e934. doi: 10.1038/cddis.2013.462

Fielitz, J., Kim, M. S., Shelton, J. M., Qi, X., Hill, J. A., Richardson, J. A., et al. (2008). Requirement of protein kinase D1 for pathological cardiac remodeling. Proc. Natl. Acad. Sci. U.S.A. 105, 3059-3063. doi: 10.1073/pnas.0712265105

Friedrich, K. L., Giese, K. C., Buan, N. R., and Vierling, E. (2015). Interactions between small heat shock protein subunits and substrate in small heat shock protein-substrate complexes. J. Biol. Chem. 279, 1080-1089. doi: 10.1074/jbc.M311104200

Fukasawa, H., Yamamoto, T., Suzuki, H., Togawa, A., Ohashi, N., Fujigaki, Y., et al. (2004). Treatment with anti-TGF- $\beta$ antibody ameliorates chronic progressive nephritis by inhibiting Smad/TGF- $\beta$ signaling. Kidney Int. 65 , 63-74. doi: 10.1111/j.1523-1755.2004.00393.x

Gao, A. E., Sullivan, K. E., and Black, L. D. (2016). Lysyl oxidase expression in cardiac fibroblasts is regulated by $\alpha 2 \beta 1$ integrin interactions with the cellular microenvironment. Biochem. Biophys. Res. Commun. 475, 70-75. doi: 10.1016/j.bbrc.2016.05.037

Gao, C., and Wang, Y. (2016). Positive role for a negative calcineurin regulator in cardiac hypertrophy. Hypertension 67, 841-842. doi: 10.1161/HYPERTENSIONAHA.116.07140

Georgieva, D., Kardas, A., Buck, F., Perbandt, M., and Betzel, C. (2008). Contribution of IKr and IK1 to ventricular repolarization in canine and human myocytes: is there any influence of action potential duration? Basic Res. Cardiol. 104, 33-41. doi: 10.1007/s00395-008-0730-3

Gerdes, A. M., and Capasso, J. M. (1995). Structural remodeling and mechanical dysfunction of cardiac myocytes in heart failure. J. Mol. Cell. Cardiol. 27, 849-856. doi: 10.1016/0022-2828(95)90000-4

Gjymishka, A., Pi, L., Oh, S. H., Jorgensen, M., Liu, C., Protopapadakis, Y., et al. (2016). miR-133b regulation of connective tissue growth factor: a novel mechanism in liver pathology. Am. J. Pathol. 186, 1092-1102. doi: 10.1016/j.ajpath.2015.12.022

Gong, K., Chen, Y. F., Li, P., Lucas, J. A., Hage, F. G., Yang, Q., et al. (2011). Transforming growth factor- $\beta$ inhibits myocardial PPAR $\gamma$ expression in pressure overload-induced cardiac fibrosis and remodeling in mice. $J$. Hypertens. 29, 1810-1819. doi: 10.1097/HJH.0b013e32834a4d03

Goren, Y., Meiri, E., Hogan, C., Mitchell, H., Lebanony, D., Salman, N., et al. (2014). Relation of reduced expression of MiR-150 in platelets to atrial fibrillation in patients with chronic systolic heart failure. Am. J. Cardiol. 113, 976-981. doi: 10.1016/j.amjcard.2013.11.060

Granjon, A., Gustin, M. P., Rieusset, J., Lefai, E., Meugnier, E., Güller, I., et al. (2009). The microRNA signature in response to insulin reveals its implication in the transcriptional action of insulin in human skeletal muscle and the role of a sterol regulatory element-binding protein-1c/myocyte enhancer factor $2 \mathrm{C}$ pathway. Diabetes 58, 2555-2564. doi: 10.2337/db09-0165
Guo, T. S., Zhang, J., Mu, J. J., Liu, F. Q., Yuan, Z. Y., Ren, K. Y., et al. (2014). Highsalt intake suppressed microRNA-133a expression in Dahl SS rat myocardium. Int. J. Mol. Sci. 15, 10794-10805. doi: 10.3390/ijms150610794

Guo, Y., Li, X., Lin, C., Zhang, Y., Hu, G., Zhou, J., et al. (2015). MicroRNA133b inhibits connective tissue growth factor in colorectal cancer and correlates with the clinical stage of the disease. Mol. Med. Rep. 11, 2805-2812. doi: $10.3892 / \mathrm{mmr} .2014 .3075$

Han, B., Zhao, J. Y., Wang, W. T., Li, Z. W., He, A. P., and Song, X. Y. (2017). Cdc42 Promotes schwann cell proliferation and migration through $W n t / \beta$-Catenin and p38 MAPK signaling pathway after sciatic nerve injury. Neurochem. Res. 42, 1-8. doi: 10.1007/s11064-017-2175-2

He, B., Jian, X., Ren, A. J., Zhang, Y. F., Hao, Z., Min, C., et al. (2011). Role of miR-1 and miR-133a in myocardial ischemic postconditioning. J. Biomed. Sci. 18, 18-22. doi: 10.1186/1423-0127-18-22

Heineke, J., and Molkentin, J. D. (2006). Regulation of cardiac hypertrophy by intracellular signalling pathways. Nat. Rev. Mol. Cell Biol. 7, 589-600. doi: 10.1038/nrm1983

Hinz, B., Celetta, G., Tomasek, J. J., Gabbiani, G., and Chaponnier, C. (2001). Alpha-smooth muscle actin expression upregulates fibroblast contractile activity. Mol. Biol. Cell 12, 2730-2741. doi: 10.1091/mbc.12.9.2730

Hinz, B., Phan, S. H., Thannickal, V. J., Prunotto, M., Desmoulière, A., Varga, J., et al. (2012). Recent developments in myofibroblast biology: paradigms for connective tissue remodeling. Am. J. Pathol. 180, 1340-1355. doi: 10.1016/j.ajpath.2012.02.004

Hong, Y., Cao, H., Wang, Q., Ye, J., Sui, L., Feng, J., et al. (2016). MiR-22 may suppress fibrogenesis by targeting TGF $\beta \mathrm{R}$ I in cardiac fibroblasts. Cell. Physiol. Biochem. Int. J. Exp. Cell. Physiol. Biochem. Pharmacol. 40, 1345-1353. doi: $10.1159 / 000453187$

Hua, Y., Zhang, Y., and Ren, J. (2012). IGF-1 deficiency resists cardiac hypertrophy and myocardial contractile dysfunction: role of microRNA-1 and microRNA133a. J. Cell. Mol. Med. 16, 83-95. doi: 10.1111/j.1582-4934.2011.01307.x

Huang, M., Yang, H., Zhu, L., Li, H., Zhou, J., and Zhou, Z. (2016). Inhibition of connective tissue growth factor attenuates paraquat-induced lung fibrosis in a human MRC-5 cell line. Environ. Toxicol. 31, 1620-1626. doi: $10.1002 /$ tox.22166

Huang, X., Dai, Z., Cai, L., Sun, K., Cho, J., Albertine, K. H., et al. (2016). Endothelial p110 $\gamma$ PI3K mediates endothelial regeneration and vascular repair following inflammatory vascular injury. Circulation 133, 1093-1118. doi: 10.1161/CIRCULATIONAHA.115.020918

Huang, Y., Qi, Y., Du, J. Q., and Zhang, D. F. (2014). MicroRNA-34a regulates cardiac fibrosis after myocardial infarction by targeting Smad4. Expert Opin. Ther. Targets 18, 1355-1365. doi: 10.1517/14728222.2014.961424

Huang, Z. P., Chen, J., Seok, H. Y., Zhang, Z., Kataoka, M., Hu, X., et al. (2013). MicroRNA-22 regulates cardiac hypertrophy and remodeling in response to stress. Circ. Res. 112, 1234-1243. doi: 10.1161/CIRCRESAHA.112.300682

Huo, R., Sheng, Y., Guo, W. T., and Dong, D. L. (2014). The potential role of $\mathrm{Kv} 4.3 \mathrm{~K}+$ channel in heart hypertrophy. Channels 8, 203-209. doi: $10.4161 /$ chan. 28972

Ivey, K. N., Muth, A., Arnold, J., King, F. W., Yeh, R. F., Fish, J. E., et al. (2008). MicroRNA regulation of cell lineages in mouse and human embryonic stem cells. Cell Stem Cell 2, 219-229. doi: 10.1016/j.stem.2008.01.016

Izarra, A., Moscoso, I., Levent, E., Cañón, S., Cerrada, I., Díez-Juan, A., et al. (2014). miR-133a enhances the protective capacity of cardiac progenitors cells after myocardial infarction. Stem Cell Rep. 3, 1029-1042. doi: 10.1016/j.stemcr.2014.10.010

Jabr, R. I., Hatch, F. S., Salvage, S. C., Orlowski, A., Lampe, P. D., and Fry, C. H. (2016). Regulation of gap junction conductance by calcineurin through $\mathrm{Cx} 43$ phosphorylation: implications for action potential conduction. Pflügers Archiv. Eur. J. Physiol. 468, 1945-1955. doi: 10.1007/s00424-016-1885-7

Jayawardena, T. M., Egemnazarov, B., Finch, E. A., Zhang, L., Payne, J. A., Pandya, K., et al. (2012). MicroRNA-mediated in vitro and in vivo direct reprogramming of cardiac fibroblasts to cardiomyocytes. Circ. Res. 110, 1465-1473. doi: 10.1161/CIRCRESAHA.112.269035

Jeon, Y. J., Kim, O. J., Kim, S. Y., Oh, S. H., Oh, D., Kim, O. J., et al. (2013). Association of the miR-146a, miR-149, miR-196a2, and miR-499 polymorphisms with ischemic stroke and silent brain infarction risk. Arterioscler. Thromb. Vasc. Biol. 33, 420-430. doi: 10.1161/ATVBAHA.112.300251 
Jeyaraj, D., Wilson, L. D., Zhong, J., Flask, C., Saffitz, J. E., Deschênes, I., et al. (2007). Mechanoelectrical feedback as novel mechanism of cardiac electrical remodeling. Circulation 115, 3145-3155. doi: 10.1161/CIRCULATIONAHA.107.688317

John, B., Stiles, M. K., Kuklik, P., Chandy, S. T., Young, G. D., Mackenzie, L., et al. (2008). Electrical remodelling of the left and right atria due to rheumatic mitral stenosis. Eur. Heart J. 29, 2234-2243. doi: 10.1093/eurheartj/ehn329

Kamireddy, S., Agarwal, S. K., Adelstein, E., Jain, S., and Saba, S. (2009). Correlation of electrical and mechanical reverse remodeling after cardiac resynchronization therapy. Ann. Noninvasive Electrocardiol. 14, 153-157. doi: 10.1111/j.1542-474X.2009.00290.x

Kamo, T., Akazawa, H., and Komuro, I. (2015). Cardiac nonmyocytes in the hub of cardiac hypertrophy. Circ. Res. 117, 89-98. doi: 10.1161/CIRCRESAHA.117.305349

Kang, J. S., Bae, G. U., Yi, M. J., Yang, Y. J., Oh, J. E., Takaesu, G., et al. (2008). A Cdo-Bnip-2-Cdc42 signaling pathway regulates $\mathrm{p} 38 \alpha / \beta$ MAPK activity and myogenic differentiation. J. Cell Biol. 182, 497-507. doi: 10.1083/jcb.200801119

Kim, J. Y., An, H. J., Kim, W. H., Gwon, M. G., Gu, H., Park, Y. Y., et al. (2011). Anti-fibrotic effects of synthetic oligodeoxynucleotide for TGF- $\beta 1$ and Smad in an animal model of liver cirrhosis. Mol. Ther. Nucleic Acids 8, 250-263. doi: 10.1016/j.omtn.2017.06.022

Kodama, H., Fukuda, K., Pan, J., Makino, S., Baba, A., Hori, S., et al. (1997). Leukemia inhibitory factor, a potent cardiac hypertrophic cytokine, activates the JAK/STAT pathway in rat cardiomyocytes. Circ. Res. 81, 656-663. doi: 10.1161/01.RES.81.5.656

Konno, T., and Seidman, C. E. (2010). Heterogeneous myocyte enhancer factor2 (Mef2) activation in myocytes predicts focal scarring in hypertrophic cardiomyopathy. Proc. Natl. Acad. Sci. U.S.A. 107, 18097-18102. doi: $10.1073 /$ pnas. 1012826107

Kook, H., Lepore, J. J., Gitler, A. D., Lu, M. M., Yung, W. M., Mackay, J., et al. (2003). Cardiac hypertrophy and histone deacetylase-dependent transcriptional repression mediated by the atypical homeodomain protein Hop. J. Clin. Invest. 112, 863-871. doi: 10.1172/JCI19137

Kuwabara, Y., Horie, T., Baba, O., Watanabe, S., Nishiga, M., Usami, S., et al. (2015). MicroRNA-451 exacerbates lipotoxicity in cardiac myocytes and high-fat diet-induced cardiac hypertrophy in mice through suppression of the LKB1/AMPK pathway. Circ. Res. 116, 279-288. doi: 10.1161/CIRCRESAHA.116.304707

Lane, A. A., and Chabner, B. A. (2016). Histone deacetylase inhibitors in cancer therapy. J. Clin. Oncol. 27, 5459-5468. doi: 10.1200/JCO.2009.22.1291

Leask, A. (2015). Getting to the heart of the matter: new insights into cardiac fibrosis. Circ. Res. 116, 1269-1276. doi: 10.1161/CIRCRESAHA.116.305381

Lee, A. S., Chen, W. Y., Chan, H. C., Chung, C. H., Peng, H. Y., Chang, C. M., et al. (2017). Electronegative LDL-mediated cardiac electrical remodeling in a rat model of chronic kidney disease. Sci. Rep. 7:40676. doi: 10.1038/srep40676

Lee, B. H., Kim, W. H., Choi, M. J., Rho, J. R., and Kim, W. G. (2015). Chronic heart failure model in rabbits based on the concept of the bifurcation/trifurcation coronary artery branching pattern. Artif. Organs 26, 360-365. doi: 10.1046/j.1525-1594.2002.06881.x

Lellouche, N., Diego, C. D., Boyle, N. G., Wiener, I., Akopyan, G., Child, J. S., et al. (2011). Relationship between mechanical and electrical remodelling in patients with cardiac resynchronization implanted defibrillators. Europace 13, 1180-1187. doi: 10.1093/europace/eur106

Li, Q., Lin, X., Yang, X., and Jiang, C. (2010). NFATc4 is negatively regulated in miR-133a-mediated cardiomyocyte hypertrophic repression. Am. J. Physiol. 298, H1340-1347. doi: 10.1152/ajpheart.00592.2009

Li, R., Liang, J., Ni, S., Zhou, T., Qing, X., Li, H., et al. (2010). A Mesenchymal-toepithelial transition initiates and is required for the nuclear reprogramming of mouse fibroblasts. Cell Stem Cell 7, 51-63. doi: 10.1016/j.stem.2010.04.014

Li, Y., Cai, X., Guan, Y., Wang, L., Wang, S., Li, Y., et al. (2016). Adiponectin Upregulates MiR-133a in cardiac hypertrophy through AMPK activation and reduced ERK1/2 phosphorylation. PLOS ONE 11:e0148482. doi: 10.1371 /journal.pone. 0148482

Li, Y. D., Hong, Y. F., Yueerguli, Y., Tang, B. P., Zhou, X. H., Guo-Jun, X. U., et al. (2015). Altered expression of hyperpolarization-activated cyclic nucleotidegated channels and microRNA -1 and -133 in patients with age-associated atrial fibrillation. Mol. Med. Rep. 12, 3243-3248. doi: 10.3892/mmr.20 15.3831
Lin, C. Y., Hsu, Y. J., Hsu, S. C., Ying, C., Lee, H. S., Lin, S. H., et al. (2015). CB1 cannabinoid receptor antagonist attenuates left ventricular hypertrophy and Akt-mediated cardiac fibrosis in experimental uremia. J. Mol. Cell. Cardiol. 85, 249-261. doi: 10.1016/j.yjmcc.2015.06.010

Lin, R. C., Weeks, K. L., Gao, X. M., Williams, R. B., Bernardo, B. C., Kiriazis, H., et al. (2010). PI3K(p110 alpha) protects against myocardial infarction-induced heart failure: identification of PI3K-regulated miRNA and mRNA. Arterioscl. Thromb. Vasc. Biol. 30, 724-732. doi: 10.1161/ATVBAHA.109.201988

Liu, L., Zhao, X., Pierre, S. V., and Askari, A. (2007). Association of PI3K-Akt signaling pathway with digitalis-induced hypertrophy of cardiac myocytes. Am. J. Physiol. Cell Physiol. 293, 1489-1497. doi: 10.1152/ajpcell.00158.2007

Liu, N., Bezprozvannaya, S., Williams, A. H., Qi, X., Richardson, J. A., Basselduby, R., et al. (2008). microRNA-133a regulates cardiomyocyte proliferation and suppresses smooth muscle gene expression in the heart. Genes Dev. 22, 3242-3254. doi: 10.1101/gad.1738708

Liu, R., and Molkentin, J. D. (2016). Regulation of cardiac hypertrophy and remodeling through the dual-specificity MAPK phosphatases (DUSPs). J. Mol. Cell. Cardiol. 101, 44-49. doi: 10.1016/j.yjmcc.2016.08.018

Liu, Y., Liang, Y., Zhang, J. F., and Fu, W. M. (2017). MicroRNA-133 mediates cardiac diseases: mechanisms and clinical implications. Exp. Cell Res. 354, 65-70. doi: 10.1016/j.yexcr.2017.03.037

Lock, F. E., Ryan, K. R., Poulter, N. S., Parsons, M., and Hotchin, N. A. (2012). Differential regulation of adhesion complex turnover by ROCK1 and ROCK2. PLoS ONE 7:e31423. doi: 10.1371/journal.pone.0031423

Lu, H., Tian, A., Wu, J., Yang, C., Xing, R., Jia, P., et al. (2014). Danshensu inhibits $\beta$-adrenergic receptors-mediated cardiac fibrosis by ROS/p38 MAPK axis. Biol. Pharm. Bull. 37, 961-967. doi: 10.1248/bpb.b13-00921

Lu, M., Zhang, Q., Deng, M., Miao, J., Guo, Y., Gao, W., et al. (2008). An analysis of human microRNA and disease associations. PLOS ONE 3:e3420. doi: 10.1371/journal.pone.0003420

Lu, Y., Zhang, Y., Wang, N., Pan, Z., Gao, X., Zhang, F., et al. (2010). MicroRNA-328 contributes to adverse electrical remodeling in atrial fibrillationclinical perspective. Circulation 122, 2378-2387. doi: 10.1161/CIRCULATIONAHA.110.958967

Lyon, R. C., Zanella, F., Omens, J. H., and Sheikh, F. (2015). Mechanotransduction in cardiac hypertrophy and failure. Circ. Res. 116, 1462-1476. doi: 10.1161/CIRCRESAHA.116.304937

Marczenke, M., Piccini, I., Mengarelli, I., Fell, J., Röpke, A., Seebohm, G. et al. (2017). Cardiac subtype-specific modeling of Kv1.5 ion channel deficiency using human pluripotent stem cells. Front. Physiol. 8:469. doi: 10.3389/fphys.2017.00469

Marketou, M., Kontaraki, J., Zacharis, E., Parthenakis, F., Margkoudakis, S., Logakis, J., et al. (2013). MiR-21 and miR-133 levels in peripheral blood mononuclear cells associate with left ventricular diastolic dysfunction in patients with diastolic heart failure. Eur. Heart J. 34, 68-68. doi: 10.1093/eurheartj/eht307.68

Massengill, M. T., Ashraf, H. M., Chowdhury, R. R., Chrzanowski, S. M., Kar, J., Warren, S. A., et al. (2016). Acute heart failure with cardiomyocyte atrophy induced in adult mice by ablation of cardiac myosin light chain kinase. Cardiovasc. Res. 111, 34-43. doi: 10.1093/cvr/cvw069

Matkovich, S. J., Wang, W., Tu, Y., Eschenbacher, W. H., Dorn, L. E., Condorelli, G., et al. (2010). MicroRNA-133a protects against myocardial fibrosis and modulates electrical repolarization without affecting hypertrophy in pressure-overloaded adult hearts. Circ. Res. 106, 166-175. doi: 10.1161/CIRCRESAHA.109.202176

Mishra, P. K., Chavali, V., Sathur, P., Qipshidze, N., and Tyagi, S. (2012). P59 H $2 \mathrm{~S}$ ameliorates homocysteine mediated attenuation of miR-133a and $\beta 2$ AR in diabetic hearts. Nitric Oxide 27, S38-S38. doi: 10.1016/j.niox.2012. 08.060

Mitchell, G. F., Lamas, G. A., and Pfeffer, M. A. (1993). Ventricular Remodeling after Myocardial Infarction. Boston, MA: Springer US.

Molkentin, J. D., Lu, J. R., Antos, C. L., Markham, B., Richardson, J., Robbins, J., et al. (1998). A calcineurin-dependent transcriptional pathway for cardiac hypertrophy. Cell 93, 215-228. doi: 10.1016/S0092-8674(00)81573-1

Morgan, H. E., and Baker, K. M. (1991). Cardiac hypertrophy. Mechanical, neural, and endocrine dependence. Circulation 83, 13-25. doi: 10.1161/01.CIR.83.1.13

Morishima, M., Iwata, E., Nakada, C., Tsukamoto, Y., Takanari, H., Miyamoto, S., et al. (2016). Atrial Fibrillation-Mediated Upregulation of miR-30d Regulates 
Myocardial Electrical Remodeling of the G-Protein-Gated K(+) Channel, I. K.ACh. Circ. J. 80, 1346-1355. doi: 10.1253/circj.CJ-15-1276

Mueller, E. E., Momen, A., Mass,é, S., Zhou, Y. Q., Liu, J., Backx, P. H., et al. (2011). Electrical remodelling precedes heart failure in an endothelin-1-induced model of cardiomyopathy. Cardiovasc. Res. 89, 623-633. doi: 10.1093/cvr/cvq351

Muraoka, N., Yamakawa, H., Miyamoto, K., Sadahiro, T., Umei, T., Isomi, M., et al. (2014). MiR-133 promotes cardiac reprogramming by directly repressing Snail and silencing fibroblast signatures. EMBO J. 33, 1565-1581. doi: $10.15252 / \mathrm{embj} .201387605$

Myers, R., Timofeyev, V., Li, N., Kim, C., Ledford, H. A., Sirish, P., et al. (2015). Feedback mechanisms for cardiac-specific microRNAs and cAMP signaling in electrical remodeling. Circ. Arrhyth. Electrophysiol. 8, 942-950. doi: 10.1161/CIRCEP.114.002162

Na, W., Peng, G., Jianping, Z., Yanzhong, C., Shengjiang, G., and Li, C. (2012). RhoA/ROCK may involve in cardiac hypertrophy induced by experimental hyperthyroidism. Toxicol. Ind. Health 28, 831-839. doi: $10.1177 / 0748233711425069$

Nagai, T., Tanakaishikawa, M., Aikawa, R., Ishihara, H., Zhu, W., Yazaki, Y., et al. (2003). Cdc42 plays a critical role in assembly of sarcomere units in series of cardiac myocytes. Biochem. Biophys. Res. Commun. 305, 806-810. doi: 10.1016/S0006-291X(03)00838-6

Najaf, A., Sequeira, V., Kuster, D. W. D., and Velden, J. (2016). $\beta$-adrenergic receptor signalling and its functional consequences in the diseased heart. Eur. J. Clin. Invest. 46, 362-374. doi: 10.1111/eci.12598

Nakaya, M., Chikura, S., Watari, K., Mizuno, N., Mochinaga, K., Mangmool, S., et al. (2012). Induction of cardiac fibrosis by $\beta$-blocker in G protein-independent and $G$ protein-coupled receptor kinase $5 / \beta$ Arrestin2-dependent signaling pathways. J. Biol. Chem. 287, 35669-35677. doi: $10.1074 /$ jbc.M112.357871

Nandi, S. S., Duryee, M. J., Shahshahan, H. R., Thiele, G. M., Anderson, D. R., and Mishra, P. K. (2015). Induction of autophagy markers is associated with attenuation of miR-133a in diabetic heart failure patients undergoing mechanical unloading. Am. J. Transl. Res. 7, 683-696.

Newell-Litwa, K. A., Badoual, M., Asmussen, H., Patel, H., Whitmore, L., and Horwitz, A. R. (2015). ROCK1 and 2 differentially regulate actomyosin organization to drive cell and synaptic polarity. J. Cell Biol. 210, 225-242. doi: $10.1083 /$ jcb. 201504046

Ohanian, M., Humphreys, D. T., Anderson, E., Preiss, T., and Fatkin, D. (2013). A heterozygous variant in the human cardiac miR-133 gene, MIR133A2, alters miRNA duplex processing and strand abundance. BMC Genet. 14:18. doi: 10.1186/1471-2156-14-18

Olson, E. N., and Williams, R. S. (2000). Calcineurin signaling and muscle remodeling. Cell 101, 689-692. doi: 10.1016/S0092-8674(00) 80880-6

Pan, J. Y., Zhang, F., Sun, C. C., Li, S. J., Li, G., Gong, F. Y., et al. (2017). miR-134: a human cancer suppressor? Mol. Ther. Nucleic Acids 6, 140-149. doi: 10.1016/j.omtn.2016.11.003

Park, M. H., Lee, S. H., Chu, D. H., Won, K. H., Choi, B. H., Choe, H., et al. (2013). Effect of azelastine on cardiac repolarization of guinea-pig cardiomyocytes, hERG K- channel, and human L-type and T-type $\mathrm{Ca}^{2}$ - channel. J. Pharmacol. Sci. 123, 67-77. doi: 10.1254/jphs.12239FP

Parks, R. J., Bogachev, O., Mackasey, M., Ray, G., Rose, R. A., and Howlett, S. E. (2017). The impact of ovariectomy on cardiac excitation-contraction coupling is mediated through cAMP/PKA-dependent mechanisms. J. Mol. Cell. Cardiol. 111:51. doi: 10.1016/j.yjmcc.2017.07.118

Pérez-Andreu, V., Teruel, R., Corral, J., Roldán, V., García-Barber,á, N., SalloumAsfar, S., et al. (2012). miR-133a regulates vitamin K 2,3-epoxide reductase complex subunit 1 (VKORC1), a key protein in the vitamin K cycle. Mol. Med. 18, 1466-1472. doi: 10.2119/molmed.2012.00062

Priya, R., Liang, X., Teo, J. L., Duszyc, K., Yap, A. S., and Gomez, G. A. (2017). ROCK1 but not ROCK2 contributes to RhoA signaling and NMIIA-mediated contractility at the epithelial zonula adherens. Mol. Biol. Cell 28, 12-20. doi: 10.1091/mbc.e16-04-0262

Qin, W., Dong, P., Ma, C., Mitchelson, K., Deng, T., Zhang, L., et al. (2012). MicroRNA-133b is a key promoter of cervical carcinoma development through the activation of the ERK and AKT1 pathways. Oncogene 31, 4067-4075. doi: 10.1038/onc.2011.561
Renaud, L., Harris, L. G., Mani, S. K., Kasiganesan, H., Chou, J. C., Baicu, C. F., et al. (2015). HDACs regulate miR-133a expression in pressure overload induced cardiac fibrosis. Circ. Heart Fail. 8, 1094-1104. doi: 10.1161/CIRCHEARTFAILURE.114.001781

Saba, S., Mathier, M. A., Mehdi, H., Gursoy, E., Liu, T., Choi, B. R., et al. (2008). Prevention of adverse electrical and mechanical remodeling with biventricular pacing in a rabbit model of myocardial infarction. Heart Rhythm 5:124. doi: 10.1016/j.hrthm.2007.08.021

Samavarchi-Tehrani, P., Golipour, A., David, L., Sung, H. K., Beyer, T. A., Datti, A., et al. (2010). Functional genomics reveals a BMP-driven mesenchymal-toepithelial transition in the initiation of somatic cell reprogramming. Cell Stem Cell 7, 51-63. doi: 10.1016/j.stem.2010.04.015

Sang, H. Q., Jiang, Z. M., Zhao, Q. P., and Xin, F. (2015). MicroRNA-133a improves the cardiac function and fibrosis through inhibiting Akt in heart failure rats. Biomed. Pharmacother. 71, 185-189. doi: 10.1016/j.biopha.2015.02.030

Sankar, N., Detombe, P. P., and Mignery, G. A. (2014). CalcineurinNFATc regulates Type 2 inositol 1,4,5-trisphosphate receptor (InsP3R2) expression during cardiac remodeling. J. Biol. Chem. 289, 6188-6198. doi: 10.1074/jbc.M113.495242

Sayed, D., Hong, C., Chen, I. Y., Lypowy, J., and Abdellatif, M. (2007). MicroRNAs play an essential role in the development of cardiac hypertrophy. Circ. Res. 100, 416-424. doi: 10.1161/01.RES.0000257913.42552.23

Schroder, E. A., Burgess, D. E., Zhang, X., Lefta, M., Smith, J. L., Patwardhan, A., et al. (2015). The cardiomyocyte molecular clock regulates the circadian expression of Kcnh2 and contributes to ventricular repolarization. Heart Rhythm 12, 1306-1314. doi: 10.1016/j.hrthm.2015.02.019

Schutte, A. E., Conti, E., Mels, C. M., Smith, W., Kruger, R., Botha, S., et al. (2016). Attenuated IGF-1 predicts all-cause and cardiovascular mortality in a Black population: a five-year prospective study. Eur. J. Prev. Cardiol. 23, 1690-1699. doi: $10.1177 / 2047487316661436$

Seger, R., and Krebs, E. G. (1995). The MAPK signaling cascade. FASEB J. 9, 726-735. doi: 10.1096/fasebj.9.9.7601337

Shan, H., Zhang, Y., Cai, B., Chen, X., Fan, Y., Yang, L., et al. (2013). Upregulation of microRNA-1 and microRNA-133 contributes to arsenicinduced cardiac electrical remodeling. Int. J. Cardiol. 167, 2798-2805. doi: 10.1016/j.ijcard.2012.07.009

Shan, H., Zhang, Y., Lu, Y., Zhang, Y., Pan, Z., Cai, B., et al. (2009). Downregulation of miR-133 and miR-590 contributes to nicotine-induced atrial remodelling in canines. Cardiovasc. Res. 83, 465-472. doi: 10.1093/cvr/cvp130

Shi, J., Wu, X., Surma, M., Vemula, S., Zhang, L., Yu, Y., et al. (2013). Distinct roles for ROCK1 and ROCK2 in the regulation of cell detachment. Cell Death Dis. 4:e483. doi: $10.1038 /$ cddis. 2013.10

Shimizu, I., and Minamino, T. (2016). Physiological and pathological cardiac hypertrophy. J. Mol. Cell. Cardiol. 97, 245-262. doi: 10.1016/j.yjmcc.2016.06.001

Soleymaninejadian, E., Pramanik, K., and Samadian, E. (2015). Immunomodulatory properties of mesenchymal stem cells: cytokines and factors. Am. J. Reprod. Immunol. 67, 1-8. doi: 10.1111/j.1600-0897.2011.01069.x

Stitt, T. N., Drujan, D., Clarke, B. A., Panaro, F., Timofeyva, Y., Kline, W. O., et al. (2004). The IGF-1/PI3K/Akt pathway prevents expression of muscle atrophyinduced ubiquitin ligases by inhibiting FOXO transcription factors. Mol. Cell 14, 395-403. doi: 10.1016/S1097-2765(04)00211-4

Sun, L., Sun, S., Zeng, S., Li, Y., Pan, W., and Zhang, Z. (2015). Expression of circulating microRNA-1 and microRNA-133 in pediatric patients with tachycardia. Mol. Med. Rep. 11, 4039-4046. doi: 10.3892/mmr. 2015.3246

Sun, M., Liao, B., Tao, Y., Chen, H., Xiao, F., Gu, J., et al. (2016). Calcineurin-NFAT signaling controls somatic cell reprogramming in a stage-dependent manner. $J$. Cell. Physiol. 231, 1151-1162. doi: 10.1002/jcp. 25212

Taigen, T., Dewindt, L. J., Lim, H. W., and Molkentin, J. D. (2000). Targeted inhibition of calcineurin prevents agonist-induced cardiomyocyte hypertrophy. Proc. Natl. Acad. Sci. U.S.A. 97, 1196-1201. doi: 10.1073/pnas.97.3.1196

Takano, H., Zou, Y., Akazawa, H., Toko, H., Mizukami, M., Hasegawa, H., et al. (2002). Inhibitory molecules in signal transduction pathways of cardiac hypertrophy. Hypertension Res. 25, 491-498. doi: 10.1291/hypres. 25.491 
Tao, L., Bei, Y., Chen, P., Lei, Z., Fu, S., Zhang, H., et al. (2016). Crucial role of miR-433 in regulating cardiac fibrosis. Theranostics 6, 2068-2083. doi: 10.7150/thno.15007

Teekakirikul, P., Eminaga, S., Toka, O., Alcalai, R., Wang, L., Wakimoto, H., et al. (2010). Cardiac fibrosis in mice with hypertrophic cardiomyopathy is mediated by non-myocyte proliferation and requires Tgf- $\beta$. J. Clin. Invest. 120, 3520-3529. doi: 10.1172/JCI42028

Tham, Y. K., Bernardo, B. C., Ooi, J. Y. Y., Weeks, K. L., and McMullen, J. R. (2015). Pathophysiology of cardiac hypertrophy and heart failure: signaling pathways and novel therapeutic targets. Arch. Toxicol. 89, 1401-1438. doi: 10.1007/s00204-015-1477-x

Thum, T., Gross, C., Fiedler, J., Fischer, T., Kissler, S., Bussen, M., et al. (2008). MicroRNA-21 contributes to myocardial disease by stimulating MAP kinase signalling in fibroblasts. Nature 456, 980-984. doi: 10.1038/nature 07511

Tian, J., An, X., and Niu, L. (2017). Myocardial fibrosis in congenital and pediatric heart disease. Exp. Ther. Med. 13, 1660-1664. doi: 10.3892/etm.2017.4224

Torella, D., Iaconetti, C., Catalucci, D., Ellison, G. M., Leone, A., Waring, C. D., et al. (2011). MicroRNA-133 controls vascular smooth muscle cell phenotypic switch in vitro and vascular remodeling in vivo. Circ. Res. 109, 880-893. doi: 10.1161/CIRCRESAHA.111.240150

Townley-Tilson, W. H., Callis, T. E., and Wang, D. (2010). MicroRNAs 1, 133, and 206: critical factors of skeletal and cardiac muscle development, function, and disease. Int. J. Biochem. Cell Biol. 42, 1252-1255. doi: 10.1016/j.biocel.2009.03.002

Trajkovski, M., Ahmed, K., Esau, C. C., and Stoffel, M. (2012). MyomiR133 regulates brown fat differentiation through Prdm16. Nat. Cell Biol. 14, 1330-1335. doi: $10.1038 /$ ncb2612

Travers, J. G., Kamal, F. A., Robbins, J., Yutzey, K. E., and Blaxall, B. C. (2016). Cardiac fibrosis: the fibroblast awakens. Circ. Res. 118, 1021-1040. doi: 10.1161/CIRCRESAHA.115.306565

Vidigal, J. A., and Ventura, A. (2015). The biological functions of miRNAs: lessons from in vivo studies. Trends Cell Biol. 25, 137-147. doi: 10.1016/j.tcb.2014.11.004

Walmsley, J., Rodriguez, J. F., Mirams, G. R., Burrage, K., Efimov, I. R., and Rodriguez, B. (2013). mRNA expression levels in failing human hearts predict cellular electrophysiological remodelling: a population-based simulation study. PLoS ONE 8:e56359. doi: 10.1371/journal.pone.0056359

Wang, D., Zhai, G., Ji, Y., and Jing, H. (2017). microRNA-10a targets T-box 5 to inhibit the development of cardiac hypertrophy. Int. Heart J. 58, 100-106. doi: 10.1536/ihj.16-020

Wang, D. S., Zhang, H. Q., Zhang, B., Yuan, Z. B., Yu, Z. K., Yang, T., et al. (2016). miR-133 inhibits pituitary tumor cell migration and invasion via down-regulating FOXC1 expression. Genet. Mol. Res. 15, 1-10. doi: $10.4238 /$ gmr.15017453

Wang, G. J., Guo, L. Y., Wang, H. X., and Yao, Y. S. (2017). IP3R and RyR calcium channels are involved in neonatal rat cardiac myocyte hypertrophy induced by tumor necrosis factor- $\alpha$. Am. J. Transl. Res. 9, 343-354.

Wang, Y., Li, J., Chen, H., Mo, Y., Ye, H., Luo, Y., et al. (2016). Down-regulation of miR-133a as a poor prognosticator in non-small cell lung cancer. Gene 591, 333-337. doi: 10.1016/j.gene.2016.06.001

Wen, Y., and Li, B. (2017). The conduction system and expressions of hyperpolarization-activated cyclic nucleotide-gated cation channel 4 and connexin43 expressions in the hearts of fetal day 13 mice. Biotechnol. Histochem. 92, 86-91. doi: 10.1080/10520295.2016.12 55994

Wenzel, S., Taimor, G., Piper, H. M., and Schlüter, K. (2001). Redox-sensitive intermediates mediate angiotensin II-induced p38 MAP kinase activation, AP1 binding activity, and TGF- $\beta$ expression in adult ventricular cardiomyocytes. FASEB J. 15, 2291-2293. doi: 10.1096/fj.00-0827fje

Williams, S. M., Goldenmason, L., Ferguson, B. S., Schuetze, K. B., Cavasin, M. A., Demosdavies, K., et al. (2014). Class I HDACs regulate angiotensin IIdependent cardiac fibrosis via fibroblasts and circulating fibrocytes. J. Mol. Cell. Cardiol. 67, 112-125. doi: 10.1016/j.yjmcc.2013.12.013

Wronska, A., Kurkowska-Jastrzebska, I., and Santulli, G. (2015). Application of microRNAs in diagnosis and treatment of cardiovascular disease. Acta Physiol. 213, 60-83. doi: 10.1111/apha.12416
Wu, Q. Q., Ni, J., Zhang, N., Liao, H. H., Tang, Q. Z., and Deng, W. (2017a). Andrographolide protects against aortic banding-induced experimental cardiac hypertrophy by inhibiting MAPKs signaling. Front. Pharmacol. 8:808. doi: 10.3389/fphar.2017.00808

Wu, Q. Q., Xiao, Y., Yuan, Y., Ma, Z. G., Liao, H. H., Liu, C., et al. (2017b). Mechanisms contributing to cardiac remodelling. Clin. Sci. 131, 2319-2345. doi: $10.1042 / C S 20171167$

Xiao, J. (2011). Identification of microRNA precursors based on random forest with network-level representation method of stem-loop structure. BMC Bioinformatics 12:165. doi: 10.1186/1471-2105-12-165

Xiao, J., Luo, X., Lin, H., Zhang, Y., Lu, Y., Wang, N., et al. (2011). MicroRNA miR-133 represses HERG K+ channel expression contributing to QT prolongation in diabetic hearts. J. Biol. Chem. 286, 12363-12367. doi: 10.1074/jbc.A111.700015

Xu, C., Hu, Y., Hou, L., Ju, J., Li, X., Du, N., et al. (2014). $\beta$-Blocker carvedilol protects cardiomyocytes against oxidative stress-induced apoptosis by up-regulating miR-133 expression. J. Mol. Cell. Cardiol. 75, 111-121. doi: 10.1016/j.yjmcc.2014.07.009

Xu, C., Lu, Y., Pan, Z., Chu, W., Luo, X., Lin, H., et al. (2007). The musclespecific microRNAs miR-1 and miR-133 produce opposing effects on apoptosis by targeting HSP60, HSP70 and caspase-9 in cardiomyocytes. J. Cell Sci. 120, 3045-3452. doi: 10.1242/jcs.010728

Yang, D., Zhao, D., and Chen, X. (2017). MiR-133b inhibits proliferation and invasion of gastric cancer cells by up-regulating FBN1 expression. Cancer Biomark. 19, 1-12. doi: 10.3233/CBM-160421

Yang, J., Chen, Y. N., Xu, Z. X., Mou, Y., and Zheng, L. R. (2016). Alteration of RhoA prenylation ameliorates cardiac and vascular remodeling in spontaneously hypertensive rats. Cell. Physiol. Biochem. 39, 229-241. doi: $10.1159 / 000445619$

Yin, V. P., Lepilina, A., Smith, A., and Poss, K. D. (2012). Regulation of zebrafish heart regeneration by miR-133. Dev. Biol. 365, 319-327. doi: 10.1016/j.ydbio.2012.02.018

Yin, Z., Wang, X., Zhang, L., Zhou, H., Wei, L., and Dong, X. (2016). Aspirin attenuates angiotensin II-induced cardiomyocyte hypertrophy by inhibiting the $\mathrm{Ca}(2+) / C a l c i n e u r i n-N F A T$ signaling pathway. Cardiovasc. Ther. 34, 21-29. doi: 10.1111/1755-5922.12164

Ying, C., Liu, T., Ling, H., Cheng, M., Zhou, X., Wang, S., et al. (2017). Glucose variability aggravates cardiac fibrosis by altering AKT signalling path. Diabetes Vasc. Disease Res. 14, 327-335. doi: 10.1177/1479164117698917

Yoshimatsu, Y., and Watabe, T. (2011). Roles of TGF- $\beta$ signals in endothelialmesenchymal transition during cardiac fibrosis. Int. J. Inflamm. 2011:724080 doi: 10.4061/2011/724080

Yu, H., Königshoff, M., Jayachandran, A., Handley, D., Seeger, W., Kaminski, N., et al. (2008). Transgelin is a direct target of TGF-beta/Smad3 dependent epithelial cell migration in lung fibrosis. FASEB J. 22, 1778-1789. doi: 10.1096/fj.07-083857

Yu, M., Zheng, Y., Sun, H. X., and Yu, D. J. (2012). Inhibitory effects of enalaprilat on rat cardiac fibroblast proliferation via ROS/P38MAPK/TGF- $\beta 1$ signaling pathway. Molecules 17, 2738-2751. doi: 10.3390/molecules17032738

Zaja, I., Bai, X., Liu, Y., Kikuchi, C., Dosenovic, S., Yan, Y., et al. (2014). Cdk1, PKC $\delta$ and calcineurin-mediated Drp1 pathway contributes to mitochondrial fissioninduced cardiomyocyte death. Biochem. Biophys. Res. Commun. 453, 710-721. doi: 10.1016/j.bbrc.2014.09.144

Zhang, S., Weinheimer, C., Courtois, M., Kovacs, A., Zhang, C. E., Cheng, A. M., et al. (2003). The role of the Grb2-p38 MAPK signaling pathway in cardiac hypertrophy and fibrosis. J. Clin. Invest. 111, 833-841. doi: 10.1172/JCI 16290

Zhao, X., Wang, K., Liao, Y., Zeng, Q., Li, Y., Hu, F., et al. (2015). MicroRNA-101a inhibits cardiac fibrosis induced by hypoxia via targeting TGFBRI on cardiac fibroblasts. Cell. Physiol. Biochem. Int. J. Exp. Cell. Physiol. Biochem. Pharmacol. 35, 213-226. doi: 10.1159/000369689

Zhao, Y., Samal, E., and Srivastava, D. (2005). Serum response factor regulates a muscle-specific microRNA that targets Hand2 during cardiogenesis. Nature 436, 214-220. doi: 10.1038/nature03817

Zhao, Y., Wang, C., Wu, J., Wang, Y., Zhu, W., Zhang, Y., et al. (2013). Choline protects against cardiac hypertrophy induced by increased after-load. Int. J. Biol. Sci. 9, 295-302. doi: 10.7150/ijbs.5976 
Zhou, H., Yang, H. X., Yuan, Y., Deng, W., Zhang, J. Y., Bian, Z. Y., et al. (2013). Paeoniflorin attenuates pressure overload-induced cardiac remodeling via inhibition of TGF $\beta /$ Smads and NF-кB pathways. J. Mol. Histol. 44, 357-367. doi: 10.1007/s10735-0139491-x

Zhou, L., Liu, J., Olson, P., Zhang, K., Wynne, J., and Xie, L. (2015). Tbx5 and Osr1 interact to regulate posterior second heart field cell cycle progression for cardiac septation. J. Mol. Cell. Cardiol. 85, 1-12. doi: 10.1016/j.yjmcc.2015. 05.005

Ziaeian, B., and Fonarow, G. C. (2016). Epidemiology and aetiology of heart failure. Nat. Rev. Cardiol. 13, 368-378. doi: 10.1038/nrcardio.2016.25

Zicha, S., Xiao, L., Stafford, S., Cha, T. J., Han, W., Varro, A., et al. (2004). Transmural expression of transient outward potassium current subunits in normal and failing canine and human hearts. J. Physiol. 561, 735-748. doi: 10.1113/jphysiol.2004.075861
Zwi-Dantsis, L., Huber, I., Habib, M., Winterstern, A., Gepstein, A., Arbel, G., et al. (2013). Derivation and cardiomyocyte differentiation of induced pluripotent stem cells from heart failure patients. Eur. Heart J. 34, 1575-1586. doi: 10.1093/eurheartj/ehs096

Conflict of Interest Statement: The authors declare that the research was conducted in the absence of any commercial or financial relationships that could be construed as a potential conflict of interest.

Copyright (c) $2018 \mathrm{Li}$, Zhou and Tang. This is an open-access article distributed under the terms of the Creative Commons Attribution License (CC BY). The use, distribution or reproduction in other forums is permitted, provided the original author(s) and the copyright owner(s) are credited and that the original publication in this journal is cited, in accordance with accepted academic practice. No use, distribution or reproduction is permitted which does not comply with these terms. 